\title{
Metagenomic analysis and metabolite profiling of deep-sea sediments from the Gulf of Mexico following the Deepwater Horizon oil spill
}

\author{
Nikole E. Kimes ${ }^{1+}$, Amy V. Callaghan ${ }^{2}$, Deniz F. Aktas ${ }^{2,3}$, Whitney L. Smith ${ }^{2,3}$, Jan Sunner ${ }^{2,3}$, \\ Bernard T. Golding ${ }^{4}$, Marta Drozdowska ${ }^{4}$, Terry C. Hazen ${ }^{5,6,7,8}$, Joseph M. Suflita ${ }^{2,3}$ and Pamela J. Morris ${ }^{1}$ * \\ 'Baruch Marine Field Laboratory, Belle W. Baruch Institute for Marine and Coastal Sciences, University of South Carolina, Georgetown, SC, USA \\ ${ }^{2}$ Department of Microbiology and Plant Biology, University of Oklahoma, Norman, OK, USA \\ ${ }^{3}$ Institute for Energy and the Environment, University of Oklahoma, Norman, OK, USA \\ ${ }^{4}$ School of Chemistry, Newcastle University, Newcastle upon Tyne, UK \\ ${ }^{5}$ Department of Civil and Environmental Engineering, University of Tennessee, Knoxville, TN, USA \\ ${ }^{6}$ Department of Microbiology, University of Tennessee, Knoxville, TN, USA \\ ${ }^{7}$ Department of Earth and Planetary Sciences, University of Tennessee, Knoxville, TN, USA \\ ${ }^{8}$ Ecology Department, Lawrence Berkeley National Laboratory, Berkeley, CA, USA
}

\section{Edited by:}

Rachel Narehood Austin, Bates College, USA

\section{Reviewed by:}

John Senko, The University of Akron, USA

John W. Moreau, University of Melbourne, Australia

\section{${ }^{*}$ Correspondence:}

Pamela J. Morris, Baruch Marine Field Laboratory, Belle W. Baruch Institute for Marine and Coastal Sciences, University of South Carolina, PO BOX 1630, Georgetown, SC 29442, USA. e-mail: pjmorris@belle.baruch.sc.edu

${ }^{\dagger}$ Present address:

Nikole E. Kimes, Evolutionary Genomics Group, División de Microbiología, Universidad Miguel Hernández, San Juan, Alicante, Spain.
Marine subsurface environments such as deep-sea sediments, house abundant and diverse microbial communities that are believed to influence large-scale geochemical processes. These processes include the biotransformation and mineralization of numerous petroleum constituents. Thus, microbial communities in the Gulf of Mexico are thought to be responsible for the intrinsic bioremediation of crude oil released by the Deepwater Horizon (DWH) oil spill. While hydrocarbon contamination is known to enrich for aerobic, oil-degrading bacteria in deep-seawater habitats, relatively little is known about the response of communities in deep-sea sediments, where low oxygen levels may hinder such a response. Here, we examined the hypothesis that increased hydrocarbon exposure results in an altered sediment microbial community structure that reflects the prospects for oil biodegradation under the prevailing conditions. We explore this hypothesis using metagenomic analysis and metabolite profiling of deep-sea sediment samples following the DWH oil spill. The presence of aerobic microbial communities and associated functional genes was consistent among all samples, whereas, a greater number of Deltaproteobacteria and anaerobic functional genes were found in sediments closest to the DWH blowout site. Metabolite profiling also revealed a greater number of putative metabolites in sediments surrounding the blowout zone relative to a background site located $127 \mathrm{~km}$ away. The mass spectral analysis of the putative metabolites revealed that alkylsuccinates remained below detection levels, but a homologous series of benzylsuccinates (with carbon chain lengths from 5 to 10) could be detected. Our findings suggest that increased exposure to hydrocarbons enriches for Deltaproteobacteria, which are known to be capable of anaerobic hydrocarbon metabolism. We also provide evidence for an active microbial community metabolizing aromatic hydrocarbons in deep-sea sediments of the Gulf of Mexico.

Keywords: Deepwater Horizon, metagenomics, metabolomics, oil-degradation

\section{INTRODUCTION}

The Deepwater Horizon (DWH) blowout resulted in the largest marine US oil spill to date, in which 4.1 million barrels of crude oil flowed into the depths ( $\sim 1500 \mathrm{~m}$ ) of the Gulf of Mexico (Operational Science Advisory Team, 2010). Although an estimated 78\% of the oil was depleted through either human intervention or natural means by August 2010 (Ramseur, 2010), the fate of the remaining $22 \%$ was uncertain. Evidence subsequently showed that both oil (Hazen et al., 2010; Mason et al., 2012) and gas (Kessler et al., 2011) persisted in the Gulf of Mexico water column, affecting deep-sea $(>1000 \mathrm{~m})$ microbial communities that potentially facilitate the biodegradation of residual hydrocarbons. Much less is known about the impact of anthropogenic hydrocarbons on the microbial communities of deep-sea sediments. Although much of the hydrocarbons from sub-sea oil spills and natural seeps may rise to the surface, there are water-soluble components in oil as well as hydrocarbons adhering to solid particulates that can settle in deep-sea sediments (Ramseur, 2010). After the 1979 Ixtoc I oil spill, for example, in which over three million barrels of oil flowed into the Gulf of Mexico, it is estimated that $25 \%$ of the oil was transported to the sea floor (Jernelov and Linden, 1981).

The deep-sea biosphere, including deep-sea sediments, is both one of the largest and one of the most understudied ecosystems on earth (Jørgensen, 2011). Although the global estimates 
of prokaryotic biomass supported by deep-subsurface sediments are lower than originally thought, regional variation supports the presence of abundant and diverse sub-seafloor microbial communities in continental shelf areas, such as the Gulf of Mexico (Kallmeyer etal., 2012). This is especially true for the more surficial sediment communities, such as those utilized in this study. Evidence suggests that these deep-sea sediment communities support diverse metabolic activities (D'Hondt et al., 2004, 2009), including evidence of hydrocarbon degradation in microbial communities associated with cold water hydrocarbon seeps located in the Gulf of Mexico (Joye et al., 2004; Lloyd et al., 2006, 2010; Orcutt etal., 2010). As a result, it has been suggested that the microbial communities in the Gulf of Mexico deep-sea sediment would play a role in the biodegradation of persistent oil components following the DWH blowout. Despite numerous advances pertaining to individual microorganisms capable of metabolizing hydrocarbon compounds (Seth-Smith, 2010) and community responses to natural hydrocarbon seeps (Lloyd et al., 2010; Orcutt et al., 2010), little is known about the microbial capacity for oil-degradation within deep-sea sediment communities under the circumstances presented by the DWH spill, including the extreme depth $(\sim 1500 \mathrm{~m})$ and the sudden hydrocarbon exposure.

To gain a better understanding of the sediment-associated microbial response to the DWH oil spill, deep-sea sediment cores were collected by a Lawrence Berkeley National Laboratory (LBNL) team aboard the R/V Gyre in the area surrounding the DWH oil spill between September 19 and October 10, 2010. Preliminary chemical analysis revealed that the cores closest to the DWH spill contained high levels of polycyclic aromatic hydrocarbons (PAHs; $>24,000 \mu \mathrm{g} / \mathrm{kg}$ ) compared to distant cores $(\sim 50 \mu \mathrm{g} / \mathrm{kg})$, confirming a greater exposure of the resident microflora to aromatic hydrocarbons near the DWH well (Operational Science Advisory Team, 2010). Although it is likely that the DWH oil spill contributed to the higher PAH levels observed, other sources that could have influenced these levels include natural seeps located near the DWH site and drilling fluids.

In this study, we hypothesized that increased hydrocarbon exposure results in the alteration of microbial community structure, such that it reflects the selection for organisms capable of the anaerobic metabolism of petroleum constituents. We performed metagenomic sequencing on three of the deep-sea sediment samples collected by LBNL (described above) and compared our results to a Gulf of Mexico deep-subsurface sediment metagenomic library sequenced prior to the DWH oil spill (Biddle et al., 2011). To complement the metagenomic analysis, metabolic profiling was used to detect homologous series of putative signature metabolites associated with anaerobic hydrocarbon biodegradation. Our data indicated significant differences among the microbial communities examined in this study compared to those detected prior to the DWH oil spill. Moreover, the metabolite profiling revealed significantly more putative metabolites in the two samples closest to the DWH site relative to the more distant background site. These findings were consistent with the metagenomic data showing an increase in the number of functional genes associated with anaerobic hydrocarbon degradation in samples closest to the DWH.

\section{MATERIALS AND METHODS SAMPLE COLLECTION}

Deep-sea sediment cores were collected by LBNL from the area surrounding the DWH oil spill in the Gulf of Mexico during six cruises by the R/V Gyre from September 16 to October 20, 2010 (Operational Science Advisory Team, 2010). An OSIL Mega corer (Bowers and Connelly) was used to collect deepsea sediment cores, and overlying water was siphoned off using a portable peristaltic pump. The capped sediment cores were frozen at $-80^{\circ} \mathrm{C}$ and shipped on dry ice to the LBNL where the cores were sectioned while frozen. The three cores utilized in this study were designated SE-20101017-GY-D040S-BC-315 (GoM315); SE-20101017-GY-D031S-BC-278 (GoM278); and SE20100921-GY-FFMT4-BC-023 (GoM023). GoM315 and GoM278 were located near the DWH well (0.5 and $2.7 \mathrm{~km}$, respectively), while GoM023 was located at a distance of $127 \mathrm{~km}$ from the DWH well (Figure 1). One-half of each core (GoM315, GoM278, and GoM023), approximately $5^{\prime \prime}$ diameter and $1^{\prime \prime}$ thick, was sent on dry ice to the University of South Carolina Baruch Marine Field Laboratory in Georgetown, SC, USA. Upon arrival they were further subsectioned in half using sterile razorblades in a biosafety hood. One half was used for DNA extraction and metagenomic analysis, while the other half was sent on dry ice to the University of Oklahoma (Norman, OK, USA) for metabolomic analysis.

\section{DNA EXTRACTION}

Inside a biosafety hood, a sterile razor blade was used to cut a 3-4 g wedge from each of the three frozen cores (GoM315, GoM278, and GoM023). Community DNA was extracted from each core using a PowerMax ${ }^{\circledR}$ Soil DNA Isolation kit (Mo Bio Laboratories, Inc., Carlsbad, CA, USA) according to the manufacturer's instructions. The resulting DNA $(\sim 2 \mu \mathrm{g})$ from each sample was purified and concentrated via ethanol precipitation. The quality and quantity of the DNA were assessed via gel electrophoresis on a $2 \%$ agar gel with a $1 \mathrm{~kb}$ ladder and spectrophotometer analysis.

\section{METAGENOMIC SEQUENCING AND ANALYSIS}

Approximately $1 \mu \mathrm{g}$ DNA (per core sample) was sent to Engencore (University of South Carolina, Columbia, SC, USA), where highthroughput sequencing was performed using the Roche 454 FLX pyrosequencing platform. The sequencing results were recorded as SFF files and uploaded to the MetaGenome Rapid Annotation Subsystems Technology (MG-RAST) server for analysis (Meyer et al., 2008). Each file underwent quality control (QC), which included quality filtering (removing sequences with $\geq 5$ ambiguous base pairs), length filtering (removing sequences with a length $\geq 2$ standard deviations from the mean), and dereplication (removing similar sequences that are artifacts of shotgun sequencing). Organism and functional identifications were made using a BLAT [Basic Local Alignment Search Tool (BLAST)-like alignment tool] search of the integrative MG-RAST M5NR database, which is a non-redundant protein database that combines sequences from multiple common sources. All identifications were made using a maximum e-value of 1e-5, a minimum identity cutoff of $50 \%$, and a minimum alignment length of $50 \mathrm{bp}$. The hierarchical clustering/heat map comparisons were constructed in MG-RAST using dendrograms based on abundance counts for 


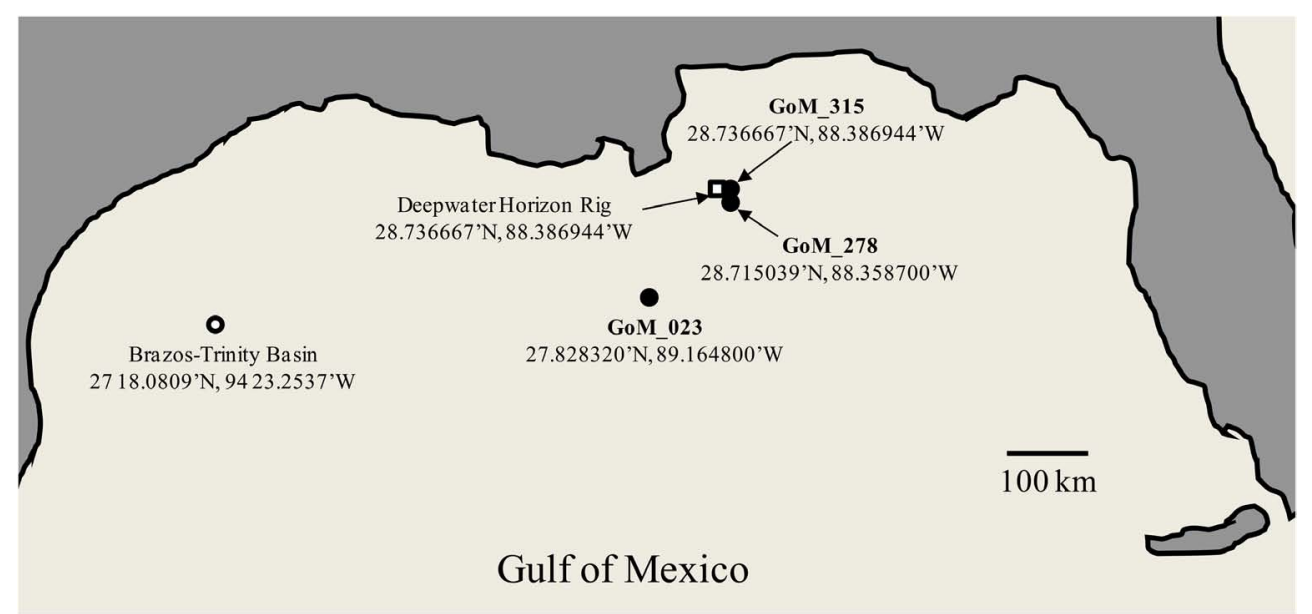

FIGURE 1 | Map of the Gulf of Mexico sampling sites. Open square - DWH rig; filled circle - sampling sites from the current study; open circle - BT Basin sampling site from Biddle et al. (2011). The Peru Margin (PM) sampling sites used for comparison are described in Biddle et al. (2008).

each category examined. Similarity/dissimilarity was determined using a Euclidean distance metric, and the resulting distance matrix was combined with ward-based clustering to produce dendrograms. Diversity indices for species richness and diversity estimates were calculated using EstimateS software (Colwell, 2006). Circular recruitment plots were created through the comparison of each metagenomic library to the whole genomes of reference organisms (Refseq genomes only) using a maximum evalue of $1 \mathrm{e}-5$ and a $\log 10$ abundance scale. Three organisms of interest were investigated: Alcanivorax borkumensis SK2 (Yakimov et al., 1998; Schneiker et al., 2006; dos Santos et al., 2010), an aerobic gammaproteobacterium that utilizes oil hydrocarbons as its exclusive source of carbon and energy and is often the most dominant bacterium in oil-polluted marine systems (Harayama et al., 1999; Kasai et al., 2001; Hara et al., 2003; Yakimov et al., 2005), Desulfatibacillum alkenivorans AK-01, a sulfate-reducing, $n$-alkane and n-alkene utilizing Deltaproteobacterium (So and Young, 1999; Callaghan et al., 2012), and Geobacter metallireducens GS-15, a metal-reducing, aromatic hydrocarbon utilizer within the Deltaproteobacteria (Lovley et al., 1993).

\section{PCR AMPLIFICATION OF FUNCTIONAL GENES}

Sediment DNA from GoM315, GoM278, GoM023 was also interrogated with nine primer set combinations specific to ass $A$ and/or bss $A$ (Callaghan et al., 2010). The ass $A$ and $b s s A$ genes encode the catalytic subunits of the anaerobic glycyl radical enzymes, alkylsuccinate synthase (ASS; also known as methylalkylsuccinate synthase, MAS; Callaghan et al., 2008; Grundmann et al., 2008) and benzylsuccinate synthase (BSS; Leuthner et al., 1998), respectively. Polymerase chain reaction (PCR) SuperMix (2X Dreamtaq, Fermentas) was used to set up $50-\mu \mathrm{L}$ reactions containing $25 \mu \mathrm{L}$ of 2X Dreamtaq mastermix, $0.4 \mu \mathrm{M}$ of each primer, $5 \mu \mathrm{L}$ of betaine (5 M stock), and $10 \mathrm{ng}$ of DNA template. A modified touchdown PCR method (Muyzer et al., 1993) was used to minimize unspecific amplification. The cycling program was as follows: $95^{\circ} \mathrm{C}$ for 4 min followed by 2 cycles at each annealing temperature (i.e., $95^{\circ} \mathrm{C}$ for $1 \mathrm{~min}, 63-52^{\circ} \mathrm{C}$ for $1 \mathrm{~min}, 72^{\circ} \mathrm{C}$ for $\left.2 \mathrm{~min}\right), 19$ cycles at the plateau annealing temperature $\left(53^{\circ} \mathrm{C}\right)$, and a final extension step at $72^{\circ} \mathrm{C}$ for $10 \mathrm{~min}$.

\section{CONSTRUCTION AND PHYLOGENETIC ANALYSIS OF assA AND bssA CLONE LIBRARIES}

Polymerase chain reaction products were purified using the Qiaquick purification kit (Qiagen) and cloned into either pCRII or pCRII-TOPO vector (Invitrogen, Carlsbad, CA, USA) following the manufacturer's instructions. For each PCR product, colonies were picked into individual wells of two 96-well microtiter plates and grown overnight. Inserts of the correct size were sequenced using the M13R priming site. After sequencing, reads were trimmed to remove vector and primer sequences before further analysis. Sequences from each respective library were assembled into operational taxonomic units (OTUs) of $\geq 97 \%$ sequence identity using Lasergene 7.2 (DNASTAR Inc., Madison, WI, USA). The ass A/bssA OTUs were aligned with ass $A$ and $b s s A$ genes from described strains for which complete sequences were available and the best BLAST matches National Center for Biotechnology Information (NCBI). Neighbor-joining trees were constructed in MEGA4 (Kumar etal., 2008) using the Tajima-Nei distance method, with pairwise deletion and performing 10,000 bootstrap replicates. The glycyl radical enzyme, pyruvate formate lyase (PFL), served as the outgroup. The DNA sequences of GoM assA and bssA OTUs were deposited in GenBank under the accession numbers JX135105 through JX135128.

\section{METABOLOMIC EXTRACTIONS AND ANALYSIS}

Approximately $25 \mathrm{~g}$ of each core sample was thawed in $20 \mathrm{~mL}$ of double-distilled sterile water and then acidified with $10 \mathrm{~N} \mathrm{HCl}$ until the $\mathrm{pH}$ was $\leq 2$. Each sample was mixed with $100 \mathrm{~mL}$ of ethyl acetate and stirred overnight. The water phase was removed and the ethyl acetate solution was dried over anhydrous $\mathrm{Na}_{2} \mathrm{SO}_{4}$, concentrated by rotary evaporation to approximately $2 \mathrm{~mL}$ and 
reduced further under a stream of $\mathrm{N}_{2}$ to a volume of $100 \mu \mathrm{L}$. Half of the extract was derivatized and analyzed by GC/MS as described previously (Aktas etal., 2010). The other half was analyzed by LC/MS with an Agilent 1290 UPLC and an Agilent 6538 AccurateMass Q-TOF with a dual electrospray ionization (ESI) ion source. A $5-\mu \mathrm{L}$ volume of each concentrated ethyl acetate solution was introduced to a ZORBAX SB-C18 column $(2.1 \mathrm{~mm} \times 100 \mathrm{~mm}$, $1.8 \mu \mathrm{m})$. A gradient method was used for the separation (0-3 min $15 \%$ acetonitrile, 3-25 min linear gradient to $95 \%$ acetonitrile in water). The flow rate was $0.4 \mathrm{~mL} / \mathrm{min}$, and the temperature of the drying gas was maintained at $325^{\circ} \mathrm{C}$. The data were analyzed using the Agilent B.04.00 MassHunter Qualitative Analysis software. A positive identification of key metabolites, such as alkylsuccinates, alkylmalonates, alkylbenzylsuccinates, and alkanoic acids, required that these were observed with the correct mass $( \pm 1 \mathrm{ppm})$, as well as with the retention times and MS/MS spectra observed for standard compounds.

\section{RESULTS}

In total, we sequenced 191.6 Mb from three deep-sea sediment samples collected after the DWH blowout (Table 1), which included two sediment cores (GoM315 and GoM278) within $3 \mathrm{~km}$ of the DWH rig and one (GoM023) $127 \mathrm{~km}$ away (Figure 1). Post QC, 125.8 Mb were designated as high-quality sequences (252,082 individual reads), resulting in an average of 84,023 individual

Table 1 | Data from the three GoM metagenomic libraries described in this study.

\begin{tabular}{|c|c|c|c|}
\hline Features & GoM315 & GoM278 & GoM023 \\
\hline $\begin{array}{l}\text { Distance from Deepwater Horizon } \\
\text { blowout }(\mathrm{km})\end{array}$ & 0.5 & 2.7 & 127.9 \\
\hline Depth below sea-level (m) & 1,464 & 1,500 & 1,614 \\
\hline $\begin{array}{l}\text { Basepairs sequenced prior to } \\
\text { QC (Mb) }\end{array}$ & 68.7 & 60.7 & 62.2 \\
\hline Individual reads prior to $\mathrm{OC}$ & 144,700 & 127,356 & 122,703 \\
\hline $\begin{array}{l}\text { Average length of reads prior to } \\
\text { OC (bp) }\end{array}$ & 474 & 476 & 506 \\
\hline Basepairs sequenced post $\mathrm{OC}(\mathrm{Mb})$ & 43.9 & 38.8 & 41.1 \\
\hline Individual reads post QC & 91,717 & 80,841 & 79,524 \\
\hline Average length of reads post $\mathrm{OC}$ (bp) & 478 & 479 & 517 \\
\hline Prokaryotes & 72,845 & 64,997 & 70,415 \\
\hline Eukaryotes & 2,056 & 1,750 & 2,376 \\
\hline Viruses & 268 & 372 & 74 \\
\hline $\begin{array}{l}\text { Functional classifications } \\
\text { (subsystems database) }\end{array}$ & 59,175 & 52,599 & 55,130 \\
\hline $\begin{array}{l}\text { Alpha diversity (species-level } \\
\text { analysis) }\end{array}$ & 1003.4 & 981.6 & 908.7 \\
\hline $\begin{array}{l}\text { Chao } 1 \text { estimate } \pm \text { SD (genus- } \\
\text { level analysis) }\end{array}$ & $593 \pm 6.4$ & $562 \pm 2.6$ & $582 \pm 4.6$ \\
\hline $\begin{array}{l}\text { Shannon index (genus-level } \\
\text { analysis) }\end{array}$ & 5.64 & 5.55 & 5.55 \\
\hline
\end{tabular}

reads (average length of $491 \mathrm{bp} / \mathrm{read}$ ) per deep-sea sediment core (Table 1).

\section{PHYLOGENETIC CLASSIFICATION}

The MG-RAST classification tool revealed that at the domain level, all three samples had similar distributions. Bacteria (9795\%) dominated, while the archaea (4.2-2.2\%) and eukaryotes $(0.8-0.6 \%)$ contributed substantially less to the sediment communities. Differences among the three samples were observed when examined at the phylum level (Figure 2). The archaea associated with the deep-sea sediment cores were predominantly Euryarchaeota, Thaumarchaeota, and Crenarchaeota (Figure 2A). The Euryarchaeota dominated $(65 \%)$ in the sample closest to the DWH rig (GoM315), but the same taxon and the Thaumarchaeota were equally represented (45\%) at GoM278. The Thaumarchaeota dominated $(55 \%)$ in the sample most distant from the spill site (GoM023).

Within the bacterial domain (Figure 2B), Proteobacteria dominated (60-65\%) all three sediment cores, followed by Firmicutes in GoM315 (9\%), Bacteroidetes in GoM278 (11\%), and Actinobacteria in GoM023 (7\%). The eukaryotic sequences represented 21 phyla from the Animalia, Fungi, Plantae, and Protista kingdoms. The Animalia phyla Arthropoda (e.g., crab and shrimp) and Chordata (e.g., fish and sharks) increased in abundance as the distance from the DWH rig increased, while the Cnidaria (e.g., corals and sponges) and Nematoda (e.g., roundworms) phyla were found only at greater abundance in the two sediment cores closest to the DWH rig. Although the number of viruses was relatively low $(0.17-0.01 \%)$, a greater number of viruses were associated with the two samples located nearest the DWH rig (GoM315 and GoM278) compared to the sample furthest away (Table 1). Alpha diversity values calculated using annotated species-level distribution increased as the distance to the DWH rig lessened. However, other diversity indices revealed similar levels of both species in richness and diversity among the samples (Table 1).

The Proteobacteria associated with each sample were examined more closely in order to evaluate the potential for both aerobic and anaerobic oil biodegradation (Figure 3), since numerous Proteobacteria spp. are known to utilize petroleum hydrocarbons (Atlas, 1981; Widdel et al., 2010). The Gammaproteobacteria was the most diverse class with the Shewanella, Marinobacter, and Pseudomonas genera being the most common. Although the Gammaproteobacteria were similarly distributed ( 33\%), the distributions of both the Alphaproteobacteria and Deltaproteobacteria varied among the three deep-sea sediment samples (Figure 3A). The Alphaproteobacteria, predominantly the Rhizobiales and Rhodobacterales orders (Figure 3B), contributed to the highest percentage (37\%) of Proteobacteria spp. in the sample furthest from the DWH rig (GoM023), while the two closer samples (GoM315 and GoM278) contained 30 and 26\%, respectively. Greater numbers of sequences associated with GoM023 were detected in numerous Alphaproteobacteria genera, including Rhizobium, Sinorhizobium, Bradyrhizobium, Roseobacter, Roseovarius, and Rhodobacter. Deltaproteobacterial distributions revealed a wider range than the Gamma- and Alphaproteobacteria, one in which the two sediment cores closest to the DWH rig (GoM315 


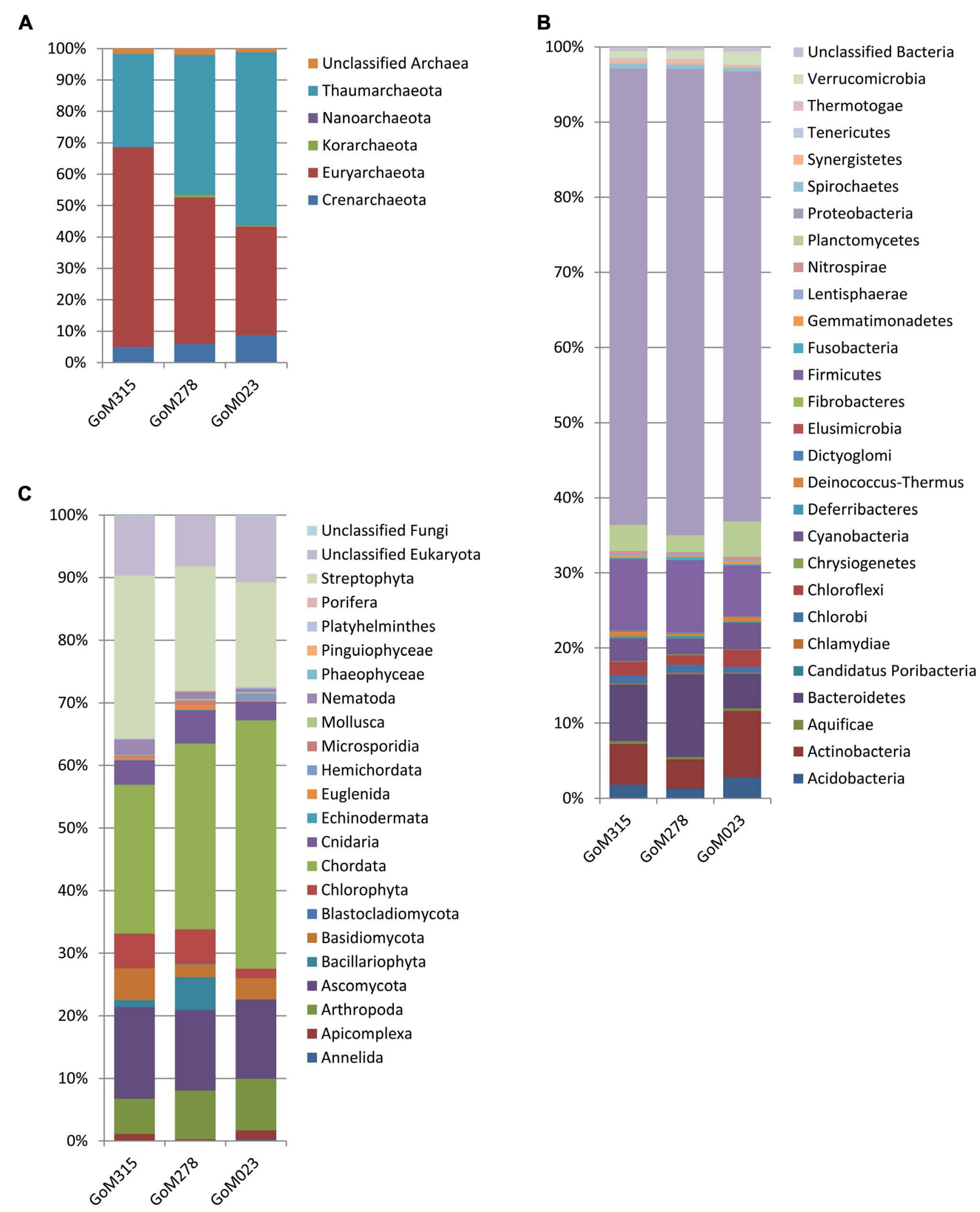

FIGURE 2 | Phylum-level organism classifications reveal differences among the three metagenomes sequenced in this study. (A) Archaea; (B) bacteria; and $(\mathbf{C})$ eukaryotes. 


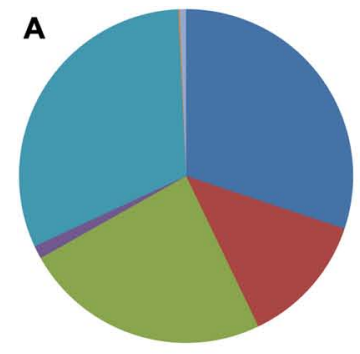

GoM315

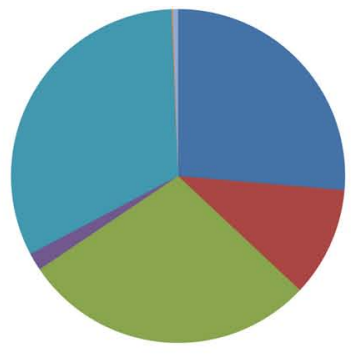

GoM278

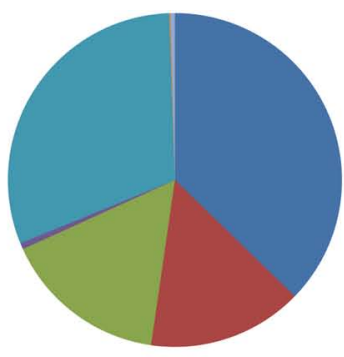

GoM023
- Alphaproteobacteria

- Betaproteobacteria

- Deltaproteobacteria

- Epsilonproteobacteria

- Gammaproteobacteria

Zetaproteobacteria

- Unclassified Proteobacteria
B

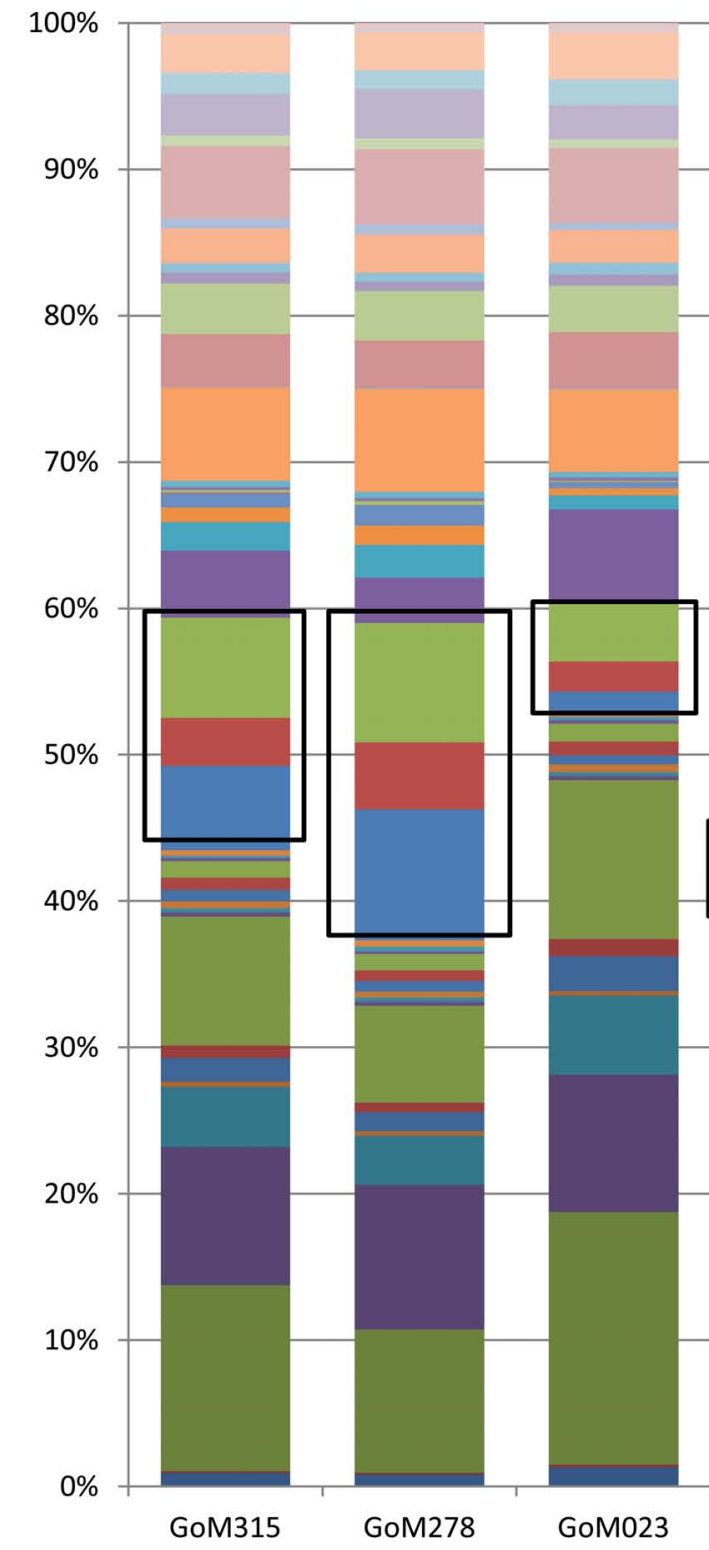

unclassified Proteobacteria

Zetaproteobacteria Mariprofundales

Gammaproteobacteria unclassified Gamma

Gammaproteobacteria Xanthomonadales

Gammaproteobacteria Vibrionales

Gammaproteobacteria Thiotrichales

Gammaproteobacteria Pseudomonadales

Gammaproteobacteria Pasteurellales

Gammaproteobacteria Oceanospirillales

- Gammaproteobacteria Methylococcales

- Gammaproteobacteria Legionellales

Gammaproteobacteria Enterobacteriales

Gammaproteobacteria Chromatiales

- Gammaproteobacteria Cardiobacteriales

- Gammaproteobacteria Alteromonadales

- Gammaproteobacteria Aeromonadales

- Gammaproteobacteria Acidithiobacillales

Epsilonproteobacteria unclassified Epsilon

- Epsilonproteobacteria Nautiliales

Epsilonproteobacteria Campylobacterales

Deltaproteobacteria unclassified Delta

- Deltaproteobacteria Syntrophobacterales

- Deltaproteobacteria Myxococcales

Deltaproteobacteria Desulfuromonadales

- Deltaproteobacteria Desulfovibrionales

Deltaproteobacteria Desulfobacterales

Deltaproteobacteria Desulfarculales

- Deltaproteobacteria Bdellovibrionales

- Betaproteobacteria unclassified Beta

- Betaproteobacteria Rhodocyclales

- Betaproteobacteria Nitrosomonadales

- Betaproteobacteria Neisseriales

- Betaproteobacteria Methylophilales

- Betaproteobacteria Hydrogenophilales

- Betaproteobacteria Gallionellales

- Betaproteobacteria Burkholderiales

- Alphaproteobacteria unclassified Alpha

- Alphaproteobacteria Sphingomonadales

- Alphaproteobacteria Rickettsiales

- Alphaproteobacteria Rhodospirillales

- Alphaproteobacteria Rhodobacterales

- Alphaproteobacteria Rhizobiales

- Alphaproteobacteria Parvularculales

- Alphaproteobacteria Caulobacterales

FIGURE 3 | Differences are observed among the sites closest to the DWH rig and the site located over a $100 \mathrm{~km}$ away when examining more of the Proteobacteria. (A) Proteobacteria classes associated with each of the three sites reveals a decrease in the
Deltaproteobacteria at the far site GoM023; (B) Proteobacteria order-level classifications identify Desulfobacterales, Desulfovibrionales, and Desulfuromonaldes as the major contributors to the difference observed. 
and GoM278) exhibited higher levels (26 and 30\%, respectively), while the furthest core (GoM023) exhibited only $16 \%$ Deltaproteobacteria (Figure 3A). No single organism accounted for the shift in Deltaproteobacteria communities, rather a myriad of genera in the Desulfobacterales (e.g., Desulfatibacillum, Desulfobacterium, and Desulfococcus), Desulfovibrionales (e.g., Desulfovibrio), and Desulfuromonadales (e.g., Geobacter, and Desulfomonas) orders displayed higher levels in the GoM315 and GoM278 samples (Figure 3B).

\section{RECRUITMENT PLOTS}

Recruitment plots, comparing sequences from each metagenomic library to the genomes of specific organisms, supported the presence of known hydrocarbon-utilizing Proteobacteria (Table 2). The analysis revealed a total of 169, 857, and 547 sequences, respectively, matching to features of the Alcanivorax borkumensis SK2 genome (Proteobacteria, Gammaproteobacteria, Oceanospirillales, Alcanivoracaceae; Yakimov et al., 1998; Schneiker etal., 2006), the Desulfatibacillum alkenivorans AK01 genome (Proteobacteria, Deltaproteobacteria, Desulfobacterales, Desulfobacteraceae; So and Young, 1999; Callaghan et al., 2012), and the G. metallireducens GS-15 genome (Proteobacteria, Deltaproteobacteria, Desulfuromonadales, Geobacteraceae; Lovley etal., 1993) in all three deep-sea sediment samples. Interestingly, matches to the aerobic hydrocarbon degrader, Alcanivorax borkumensis SK2 (51-61 sequence hits), remained consistent among all three samples; whereas, the comparison to the two anaerobic hydrocarbon degraders, Desulfatibacillum alkenivorans AK-01 (97-426 sequence hits) and G. metallireducens GS-15 (92-278 sequence hits), revealed a greater number of sequence matches to the two samples (GoM315 and GoM278) closest to the DWH well (Figure 4). Similarly, sequences recruited to Desulfococcus oleovorans Hxd3 (Table 2), a model sulfate-reducing alkane/alkene utilizer, in all three samples; however, GoM315 and GoM278 recruited a greater number of sequences (256 and 332, respectively) compared to GoM023 (79).

\section{FUNCTIONAL GENE ANALYSIS}

All three samples revealed a similar functional blueprint at the broadest level of classification (Figure 5A). Genes coding for clustering-based subsystems (15-16\%), amino acid and derivatives (9.2-9.3\%), miscellaneous (8.2-9.5\%), carbohydrates $(8.8 \%)$, and protein metabolism $(7.4-8.7 \%)$ represented the five most abundant categories when classified using the SEED database (Figure 5A). Analysis using COG classifications revealed a similar functional distribution, with the majority of sequences assigned to metabolism (45-46\%), followed by cellular processes and signaling (19-21\%), information storage and processing (17-18\%), and poorly characterized categories (15-18\%). There was genetic evidence in all three samples for the potential degradation of oil compounds, including genes vital to both the aerobic (e.g., mono- and dioxygenases) and anaerobic degradation (e.g., bss and benzoyl-CoA reductase) of compounds such as butyrate, benzoate, toluene, and alkanoic acids (Table S1 in Supplementary Material). Functional analysis of the "metabolism of aromatic compounds" subsystem provided additional evidence of a greater potential for anaerobic metabolism in the two samples nearest the DWH rig compared to the more distant sample (Figure $5 \mathbf{B}$ ). GoM315 (located $0.5 \mathrm{~km}$ from the DWH rig) exhibited the highest percentage (15\%) of anaerobic degradation genes for aromatic compounds, while GoM023 (located $128 \mathrm{~km}$ from the DWH rig) exhibited the lowest (9.9\%). Notably, the metagenomics data revealed $b s s A$ in GoM315 only, the sample closest to the DWH well, and the complete complement (subunits D-G) of benzoyl-CoA reductase genes (Egland et al., 1997) was detected in GoM315 and GoM278, but not GoM023, the site farthest from the DWH well.

\section{CLONE LIBRARIES}

Functional gene libraries supported the metagenomic analysis and also suggested a greater genetic potential for anaerobic hydrocarbon degradation at the two sites near the DWH well, with respect to the ass $A$ and $b s s A$ genes. The ass $A$ and $b s s A$ genes encode the catalytic subunits of the glycyl radical enzymes, ASS, MAS; Callaghan et al., 2008; Grundmann etal., 2008) and BSS; Leuthner et al., 1998), respectively. Based on previous studies, ASS/MAS presumably catalyzes the addition of $n$-alkanes to fumarate (Callaghan et al., 2008; Grundmann et al., 2008) to form methylalkylsuccinic acids (for review see Widdel and Grundmann, 2010), whereas BSS catalyzes the addition of aromatic hydrocarbons to fumarate to yield benzylsuccinic acids and benzylsuccinate derivatives (for review see Boll and Heider, 2010). Both ass $A$ and $b s s A$ have been used as biomarkers, in conjunction with metabolite profiling, as evidence of in situ aliphatic and aromatic hydrocarbon degradation (Beller et al., 2008; Callaghan et al., 2010; Yagi et al., 2010; Oka etal., 2011; Wawrik etal., 2012). Of the nine primer sets tested (Callaghan etal., 2010), primer set 2 (specific to $b s s A$ ) yielded four bssA OTUs in GoM278 sediment and four bssA OTUs in GoM315 sediment (Figure 6). Primer set 7 (specific to assA) yielded eight assA OTUs in GoM278 and eight ass $A$ OTUs in GoM315 (Figure 7). A comparison of the $b s s A$ and ass A OTU sequences revealed that there are unique and shared OTUs between the two sites. Sequence identities ranged from 68.8 to $100 \%$ and 63.7 to $100 \%$ for $b s s A$ and $a s s A$, respectively. Based on BlastX and BlastN, the GoM bssA clone sequences were similar to those from uncultured bacteria as well as to $b s s A$ in Thauera aromatica K172 and Azoarcus sp. T (Table S2 in Supplementary Material). Based on BlastX and BlastN, the GoM ass $A$ clone sequences were similar to those from uncultured bacteria, as well as to masD in "Aromatoleum" sp. HxN1 (Table $\mathrm{S} 2$ in Supplementary Material). The ass $A$ and $b s s A$ genes were not detected in sediment collected from the background site, GoM023, under the PCR conditions and primers tested in this study.

\section{METABOLITE PROFILING}

We specifically looked for the presence of alkylsuccinate derivatives that were presumed metabolites formed by the addition of hydrocarbon substrates across the double bond of fumarate (Biegert et al., 1996; Kropp et al., 2000; Elshahed et al., 2001; Gieg and Suflita, 2005). For example, the presence of benzyl- or alkylsuccinic acids indicates the anaerobic metabolic decay of alkylated aromatic or $n$-alkane hydrocarbons, respectively (Davidova et al., 
Table 2 | Top ranked recruitment results for each of the GoM deep-sea sediment metagenomic libraries.

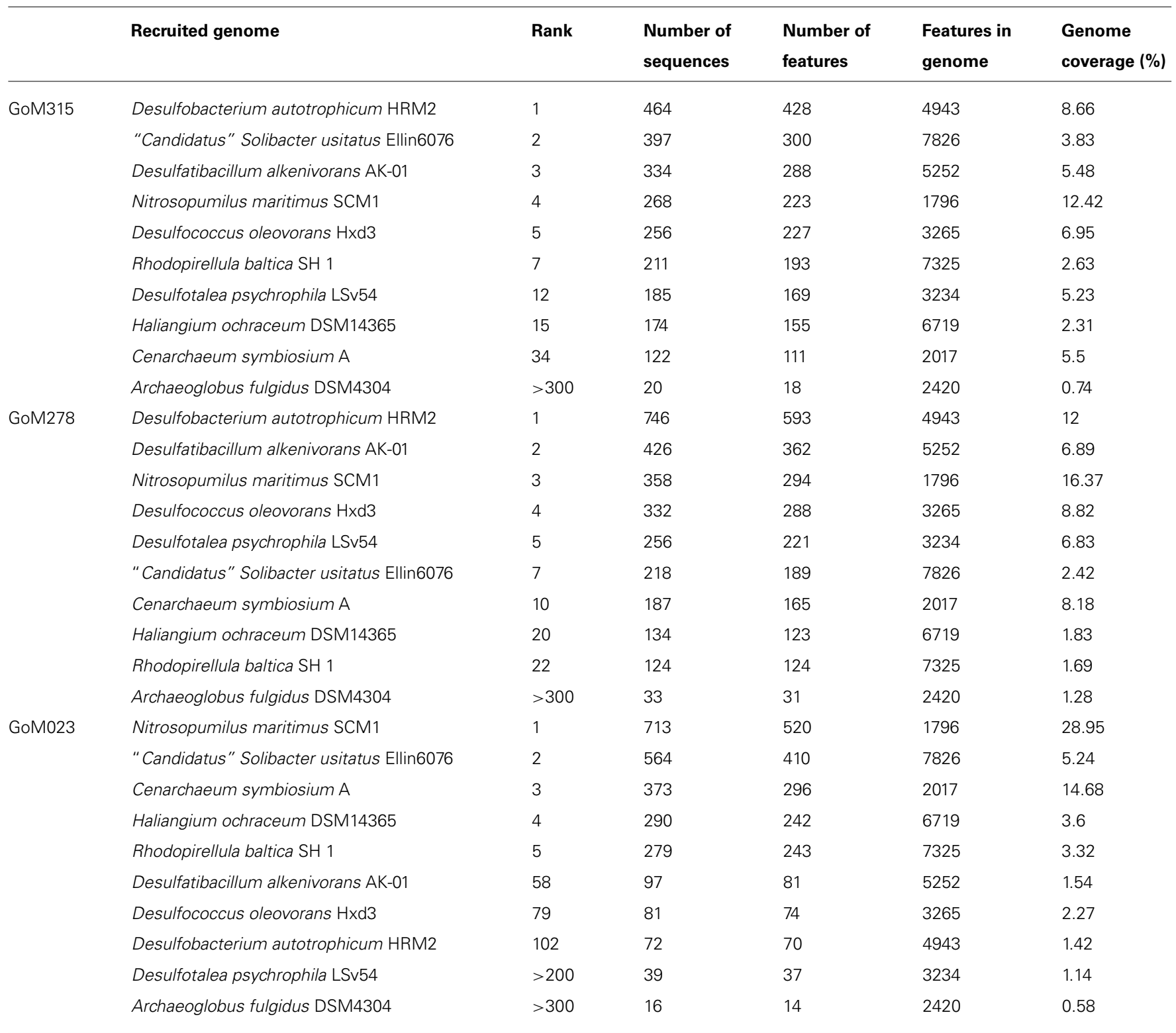

2005; Duncan et al., 2009; Parisi et al., 2009). Straight chain alkanes and alkenes with carbon lengths from C11 to C14 and from C13 to C22, respectively, were detected using GC/MS in the two sites closest to the spill site (GoM278 and GoM315). A few branched alkanes and alkenes were also observed. $n$-Alkane and $n$-alkene hydrocarbons were not detected in the background sample (GoM023). With GC/MS, alkanoic acids in GoM278 $(2.7 \mathrm{~km})$ with lengths between $\mathrm{C} 14$ and $\mathrm{C} 18$ were detected, whereas the lengths ranged from C7 to C22 in GoM315 (0.5 km). Alkylsuccinate or alkylmalonate metabolites typically associated with the anaerobic biodegradation of $n$-alkanes via "fumarate addition" were below detection levels in all samples. However, putative benzylsuccinates were identified in the samples, based on their metastable fragmentation pattern of $\approx 5 \%$ loss of $\mathrm{CO}_{2}$ and no detectable loss of $\mathrm{H}_{2} \mathrm{O}$ in $\mathrm{MS}$ mode. The highest abundances were observed for C16 to C19 benzylsuccinates (Figure 8), and their abundances were also three times higher in GoM315 (0.5 km) than in the other two samples. The presence of benzylsuccinates is consistent with the detection of $b s s A$ genotypes. Benzoate, a central metabolite of both aerobic and anaerobic hydrocarbon metabolism, was also detected in the two samples closest to the spill site.

\section{COMPARATIVE METAGENOMICS}

Comparison of our metagenomic data to that of two other deepsea metagenomes revealed a number of interesting differences. The first metagenomic study examined deep-subsurface sediment cores $\left(\mathrm{PM} 01^{\star}\right.$, PM01, PM50) from the nutrient-rich area of the Peru Margin (Biddle et al., 2008), while the second examined an oligotrophic subsurface sediment core from the Gulf of 


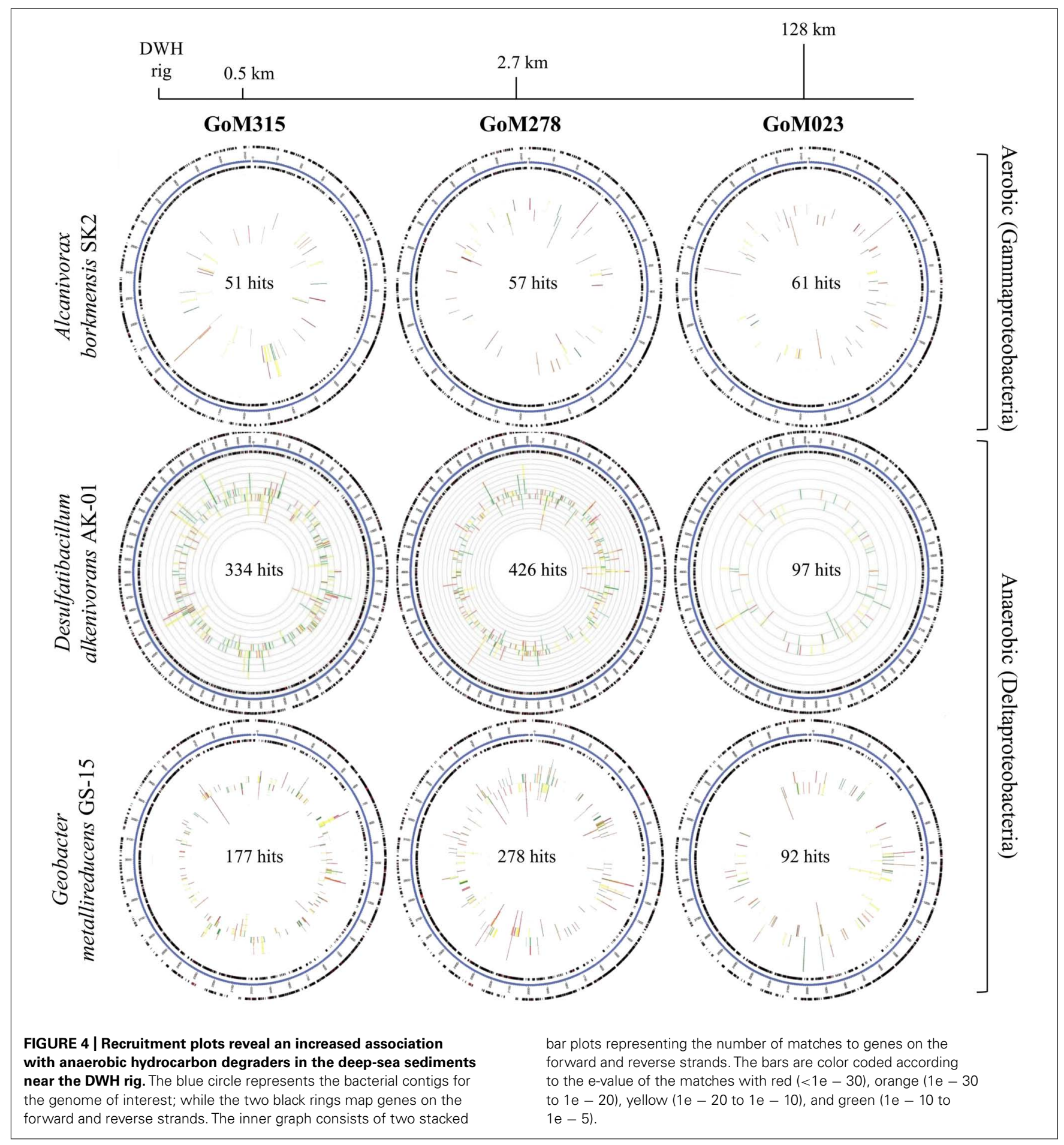

Mexico (BT Basin) prior to the DWH blowout (Biddle etal., 2011). In both studies the samples were subsurface sediments collected at a depth of two meters or greater, whereas the samples collected in this study were surficial samples collected at the interface between the water and the sediment. Distributions of organisms at the domain level were slightly different between the Peru Margin/BT Basin samples and our GoM samples, with the former harboring a greater percentage of archaea
(18.1-8.6\% compared to $2.9-3.3 \%)$ and eukaryotes (17.7-5.8\% compared to 2.6-3.3\%). At the phylum level, the Peru Margin and BT Basin data revealed a different picture from this study with a more even distribution of Proteobacteria and Firmicutes, followed by Euryarchaeota and Chloroflexi (Figure 9A). Although the functional gene patterns were similar among the three studies, sequences associated with the "metabolism of aromatic compounds" category were more abundant in all three of 

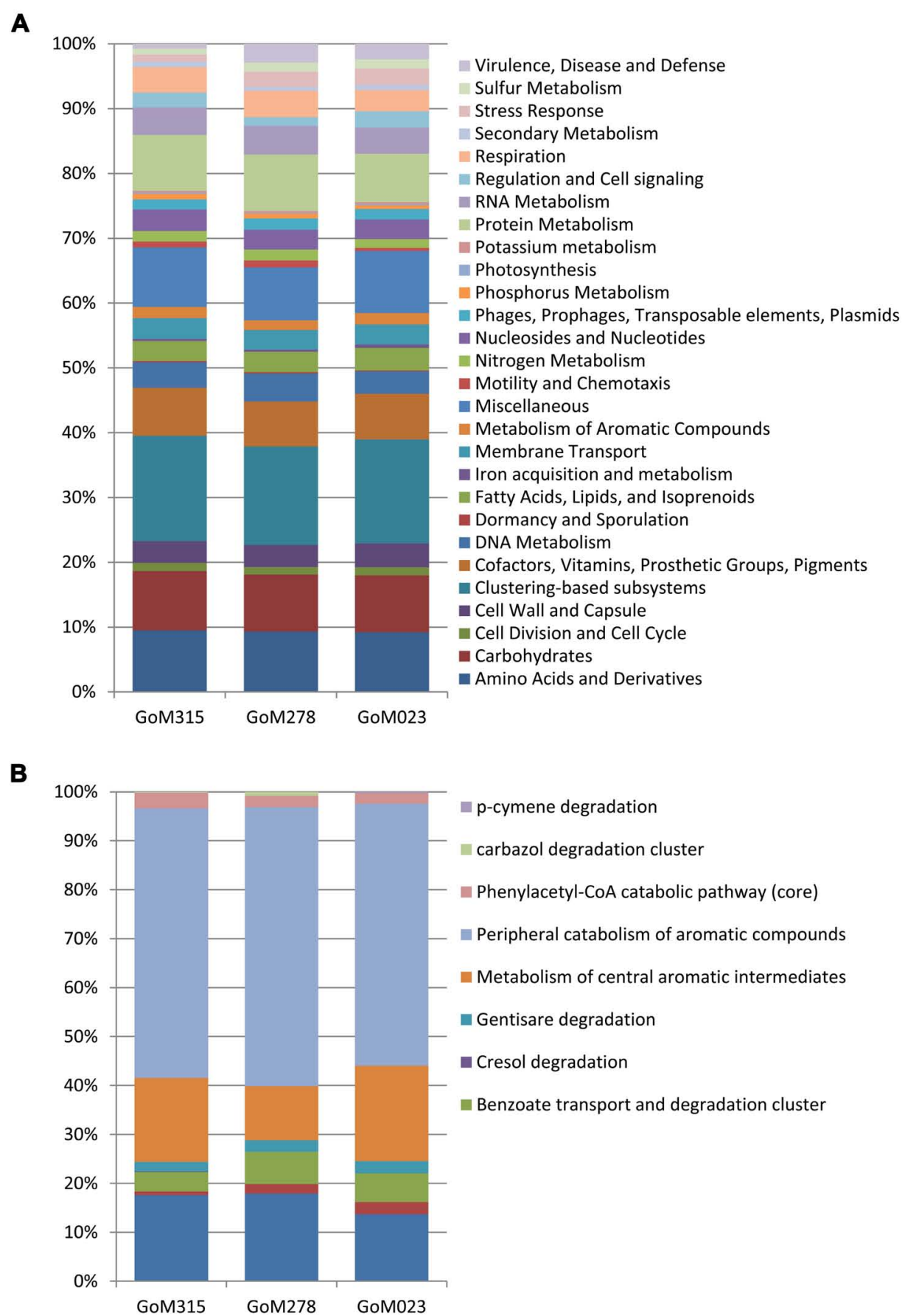

FIGURE 5 | Functional classifications of the metagenomic sequences. (A) Similar functional fingerprints are observed at the broadest subsystem classification. (B) Functional genes associated with the "metabolism of aromatic compounds" reveal a decreased association with "anaerobic degradation in aromatic compounds" in GoM023.

our samples (1.4-1.9\%) following the DWH oil spill compared to the BT Basin (0.5\%) level evaluated prior to the spill (Figure 9B). Hierarchical clustering analysis, based on subsystem functional classification, revealed geographical separation between the Peru Margin and Gulf of Mexico samples (Figure 10A). Within the Gulf of Mexico cluster, the BT Basin clustered separately from
GoM023, GoM278, and GoM315. Furthermore, GoM315 and GoM278, the samples located relatively close to the DWH rig, clustered separately from GoM023, the sample furthest from the DWH rig. A similar pattern of separation was visualized using principal component analysis (Figure 10B) with the organism classifications. 


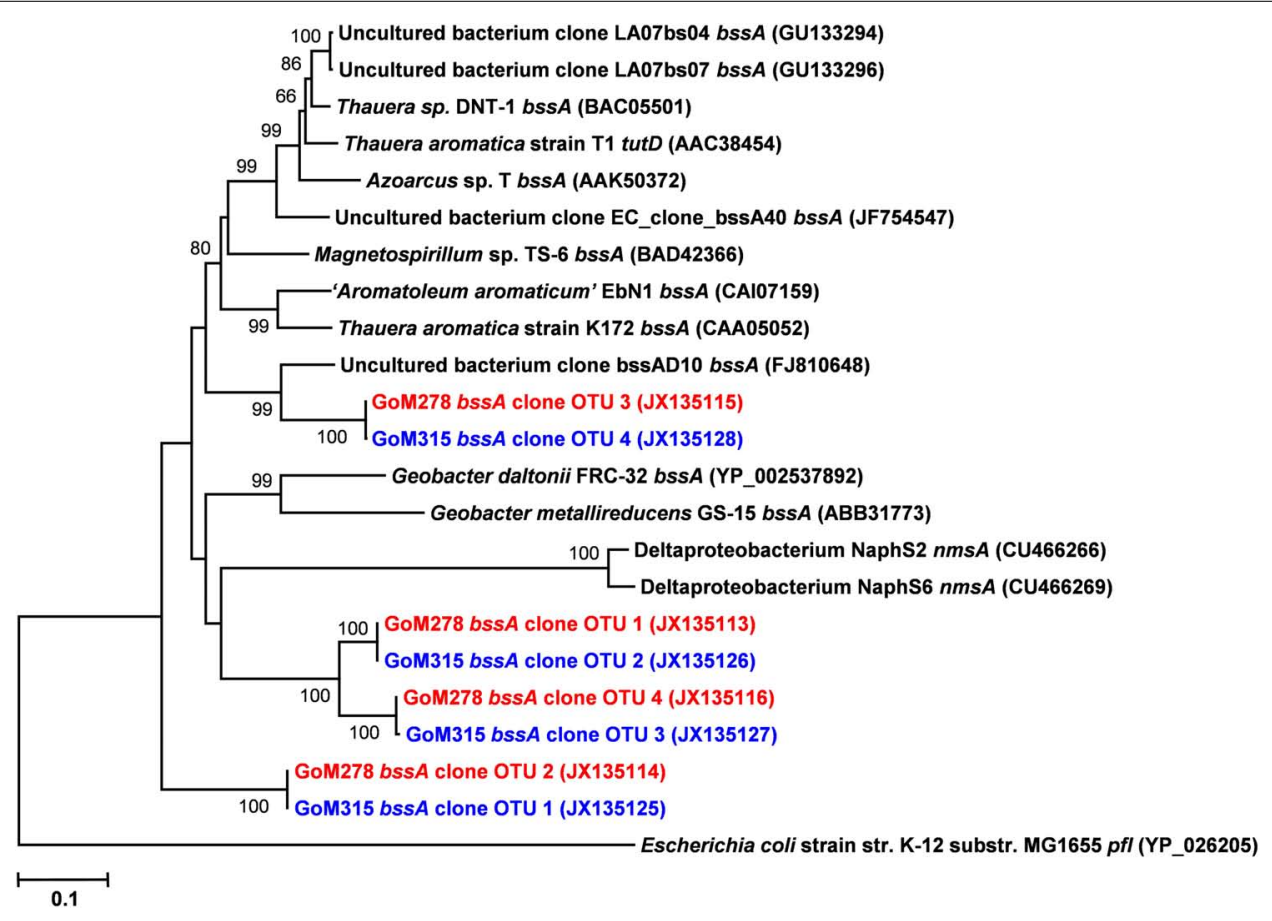

FIGURE 6 | Neighbor-joining dendrogram of bss $A$ clone sequences obtained from GoM sediments (GoM278 - red; GoM315 - blue) compared to bss $A$ sequences of reference strains and BLAST matches. The tree was constructed using the Tajima-Nei distance method (scale bar), with pairwise deletion and performing 10,000 bootstrap replicates.
Bootstrap values below 65 are not shown. pyruvate formate lyase (pfl) served as the outgroup. Numbers in parentheses represent NCBI GenBank accession numbers. bss, benzylsuccinate synthase; tut, toluene-utilizing (i.e., benzylsuccinate synthase); $n m s$, naphthylmethylsuccinate synthase.

\section{DISCUSSION}

In this study, we present three new metagenomic data sets from deep-sea sediments of the Gulf of Mexico following the DWH oil spill. Due to logistical and political circumstances surrounding the DWH oil spill, three samples were the extent of which we were able to obtain. These data, however, present a unique opportunity to examine deep-sea sediments following a massive anthropogenic hydrocarbon loading event and triples the number of metagenomic datasets previously available (one metagenome; Biddle et al., 2011) for deep-sea subsurface sediments in the Gulf of Mexico. Although the lack of replication makes it difficult to draw wide conclusions regarding the effects of hydrocarbon exposure on microbial community composition and activity, these metagenomes provide important data to make baseline observations that will need to be examined more thoroughly in future studies.

Two previous deep-sea metagenomic studies resulted in the suggestion that there is a core metagenomic structure for deepsea sediments, composed of four main microbial groups (Euryarchaeota, Proteobacteria, Firmicutes, and Chloroflexi) that can vary depending on specific parameters, such as depth, organic carbon content, and geography (Biddle et al., 2008; Biddle et al., 2011). These four microbial taxa were also detected in GoM sediment samples in the present work; however, they do not constitute the four major groups detected in this report (Proteobacteria, Bacteroidetes, Firmicutes, and Actinobacteria). Despite similarities to the microbial communities described previously (Biddle et al., 2008; Biddle et al., 2011), our cross-study comparisons via hierarchical clustering and principal component analyses reveal a distinct separation between the Peru Margin communities (Biddle et al., 2008) and both Gulf of Mexico communities (Biddle et al., 2011, and current report). This is of particular interest, since the two previous studies were subsurface samples, compared to our surficial samples. A metagenomic fosmid library of deep-sea sediments from the organic-rich Qiongdongnan Basin in the South China Sea (Hu et al., 2010) revealed a community structure that was more similar to this study than to those of the Biddle et al. $(2008,2011)$ studies. These data suggest the possibility that organic carbon content is more relevant to microbial community structure than geography. Hu et al. (2010) detected Proteobacteria as the dominant $(\sim 43 \%)$ bacterial phylum, and Deltaproteobacteria as the most abundant class within this phylum. KEGG analysis of the fosmid ends also revealed genes associated with the biodegradation pathways of numerous xenobiotics including, but not limited to dichloroethane, benzoate, biphenyl, ethylbenzene, fluorene, naphthalene, anthracene, styrene, tetrachloroethene, and gamma-hexachlorocyclohexane. The detection of genes related to the biodegradation of xenobiotic compounds in their study and ours supports the premise that deep-sea sediment microbial communities have the potential to metabolize a diverse array of organic compounds, including many that are found in oil.

Numerous bacterial species have evolved the ability to metabolize aliphatic (e.g., alkanes and alkenes) and aromatic hydrocarbons (e.g., mono- and polynuclear), with the most rapid 


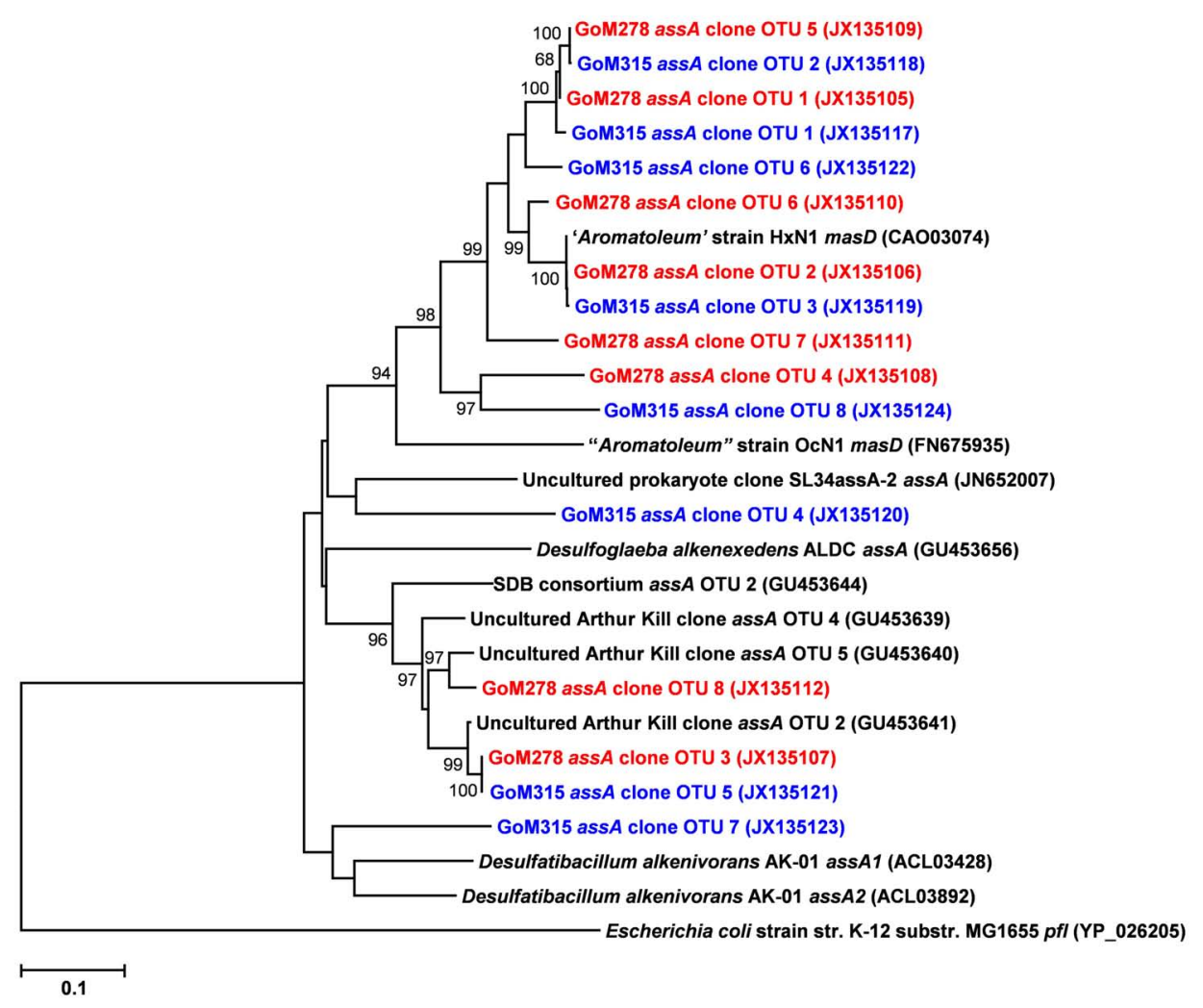

FIGURE 7 | Neighbor-joining dendrogram of ass $A$ clone sequences obtained from GoM sediments (GoM278 - red; GoM315 - blue) compared to assA/masD sequences of reference strains and BLAST matches. The tree was constructed using the Tajima-Nei distance method

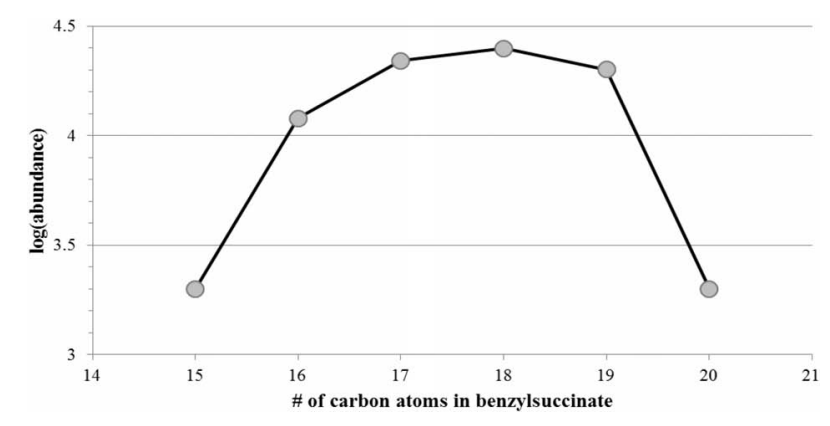

FIGURE 8 | Logarithm of abundance of benzyl succinates in the sample GoM315.

and complete degradation achieved through aerobic processes (Fritsche and Hofrichter, 2008). The majority of characterized oil-degraders within marine systems are aerobic members of the Alpha- and Gammaproteobacteria (for reviews see Head et al., 2006; Kim and Kwon, 2010) that use mono- and dioxygenases to initiate degradation (Haddock, 2010; Rojo, 2010). This includes Alcanivorax borkumensis, a ubiquitous gammaproteobacterium in marine environments, which is known to utilize aliphatic hydrocarbons (Yakimov et al., 1998; Schneiker et al., 2006; dos Santos (scale bar), with pairwise deletion and performing 10,000 bootstrap replicates. Bootstrap values below 65 are not shown. Pyruvate formate lyase ( $p f l)$ served as the outgroup. Numbers in parentheses represent NCBI GenBank accession numbers. ass, alkylsuccinate synthase; mas, methylalkylsuccinate synthase. et al., 2010). Following the DWH blow out, Oceanospirillales was shown to be the dominant bacterial orders associated with the resulting deepwater $(\sim 1100 \mathrm{~m})$ oil plume (i.e., more than $90 \%$ of the sequences were classified as Oceanospirillales, predominantly from one monophylectic lineage(Hazen et al., 2010). Our metagenomic analysis revealed the presence, in all three deep-sea sediment libraries, of bacteria belonging to the broader Oceanospirillales order, including 51-61 sequences specifically recruited to the Alcanivorax borkumensis genome in each sample (Figure 4). The abundance of Oceanospirillales, however, was relatively low ( $<2 \%$ of bacterial sequences) compared to those found in the deep water oil plume (Hazen et al., 2010; Mason et al., 2012). GoM315, GoM278, and GoM023 exhibited similar levels of Oceanospirillales spp. (1.5, 1.7, and 1.4\% of bacterial sequences, respectively) and Gammaproteobacteria in general (19, 20 , and $19 \%$ of bacterial sequences, respectively), showing no correlation to the hydrocarbon levels associated with each sample. Alphaproteobacteria associated with aerobic oil-degradation were also found at very low abundances with similar levels across the deep-sea sediment samples, including Roseovarius spp. and Maricaulis spp. ( $<0.5$ and $<0.3 \%$ of bacterial species, respectively). Nonetheless, mono- and dioxygenases were present in all three samples. These data indicate that the potential for aerobic degradation is present in these samples, albeit at much lower levels than 


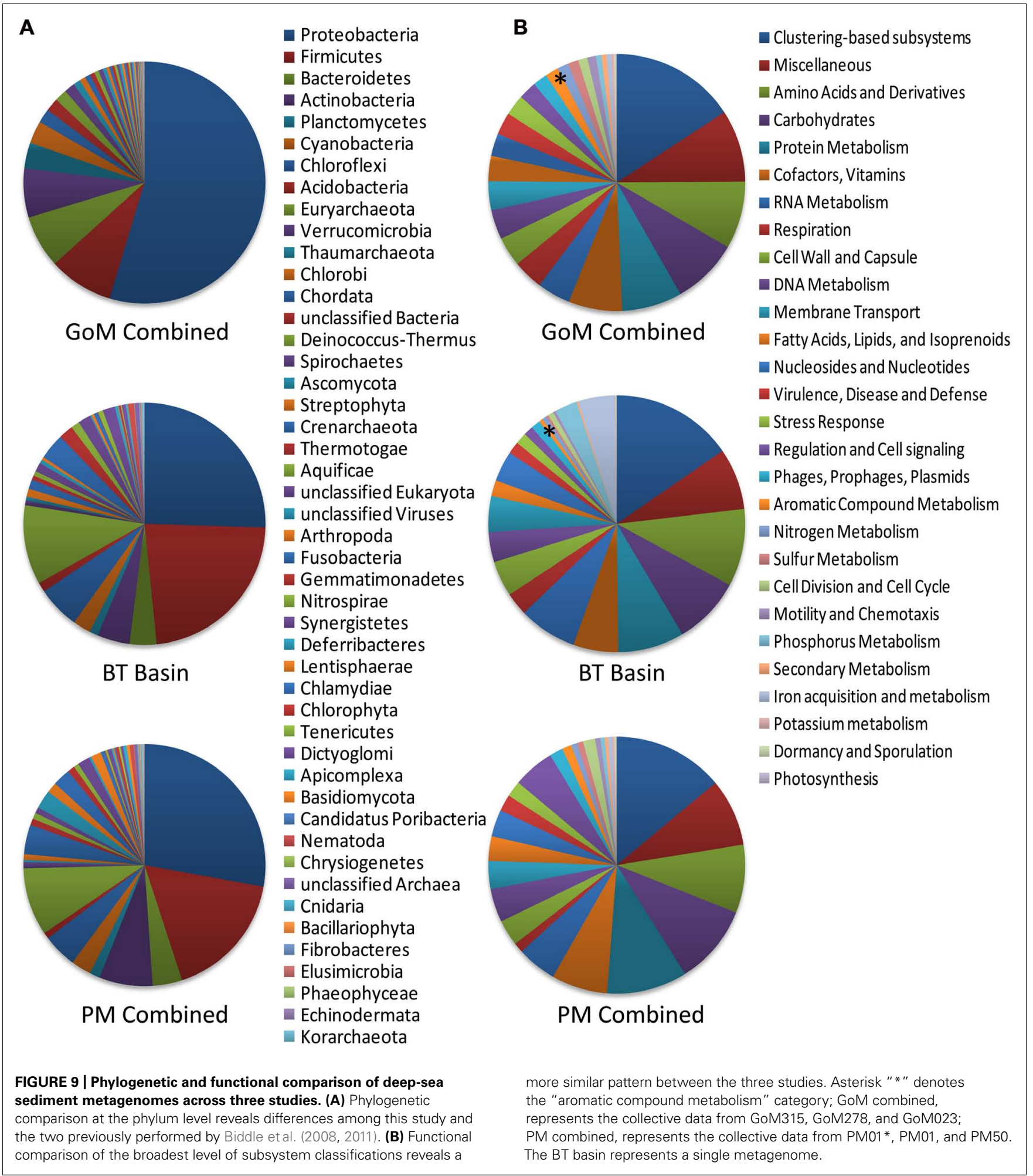

observed in the water column (Hazen et al., 2010; Mason et al., 2012), and that the level of hydrocarbon exposure did not significantly impact this potential. One potential explanation for this is that the hydrocarbons susceptible to aerobic degradation were depleted rapidly in the water column, either by dispersants or by the quick responding bacterial blooms of aerobic hydrocarbondegrading microorganisms (Hazen et al., 2010; Kessler et al., 2011). As a result, the hydrocarbon loading that occurred in the deep-sea sediments may not have promoted the growth of microorganisms capable of aerobic hydrocarbon degradation, but rather that of 
A

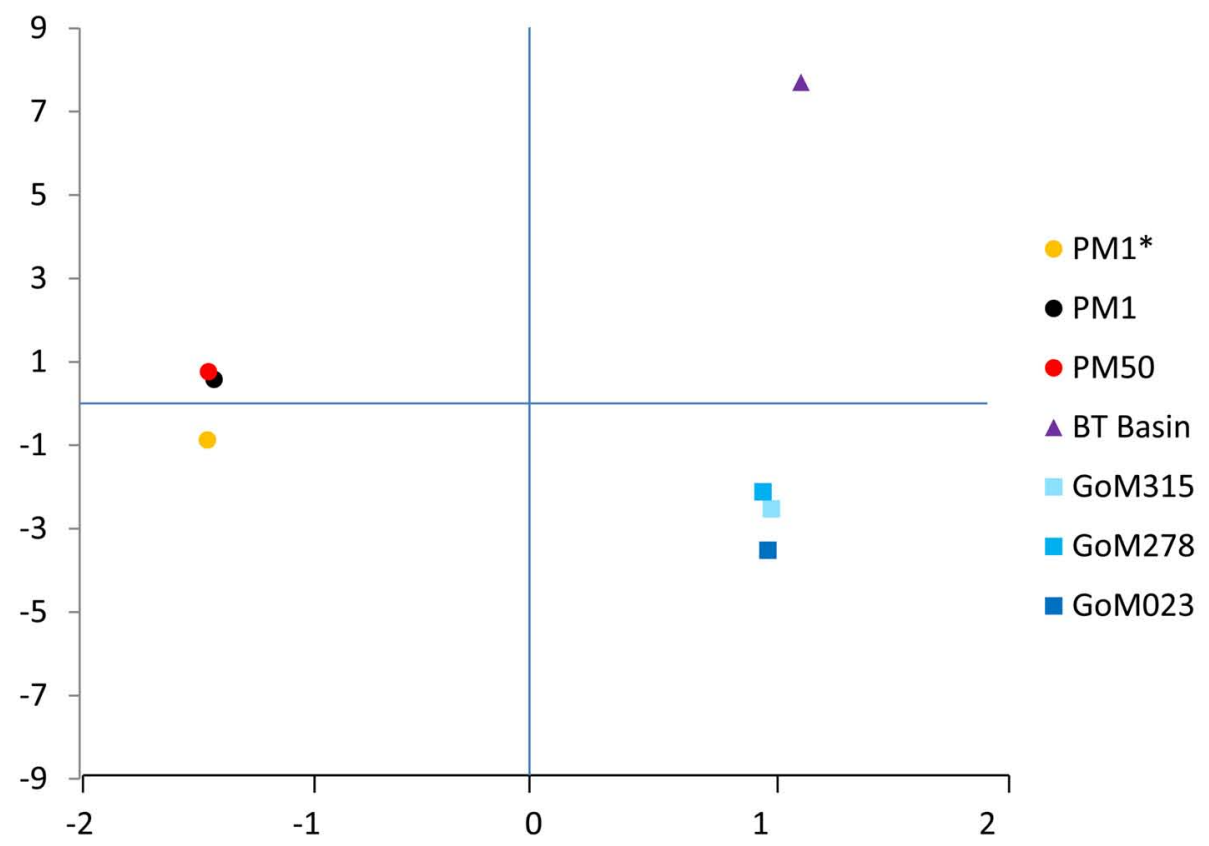

B

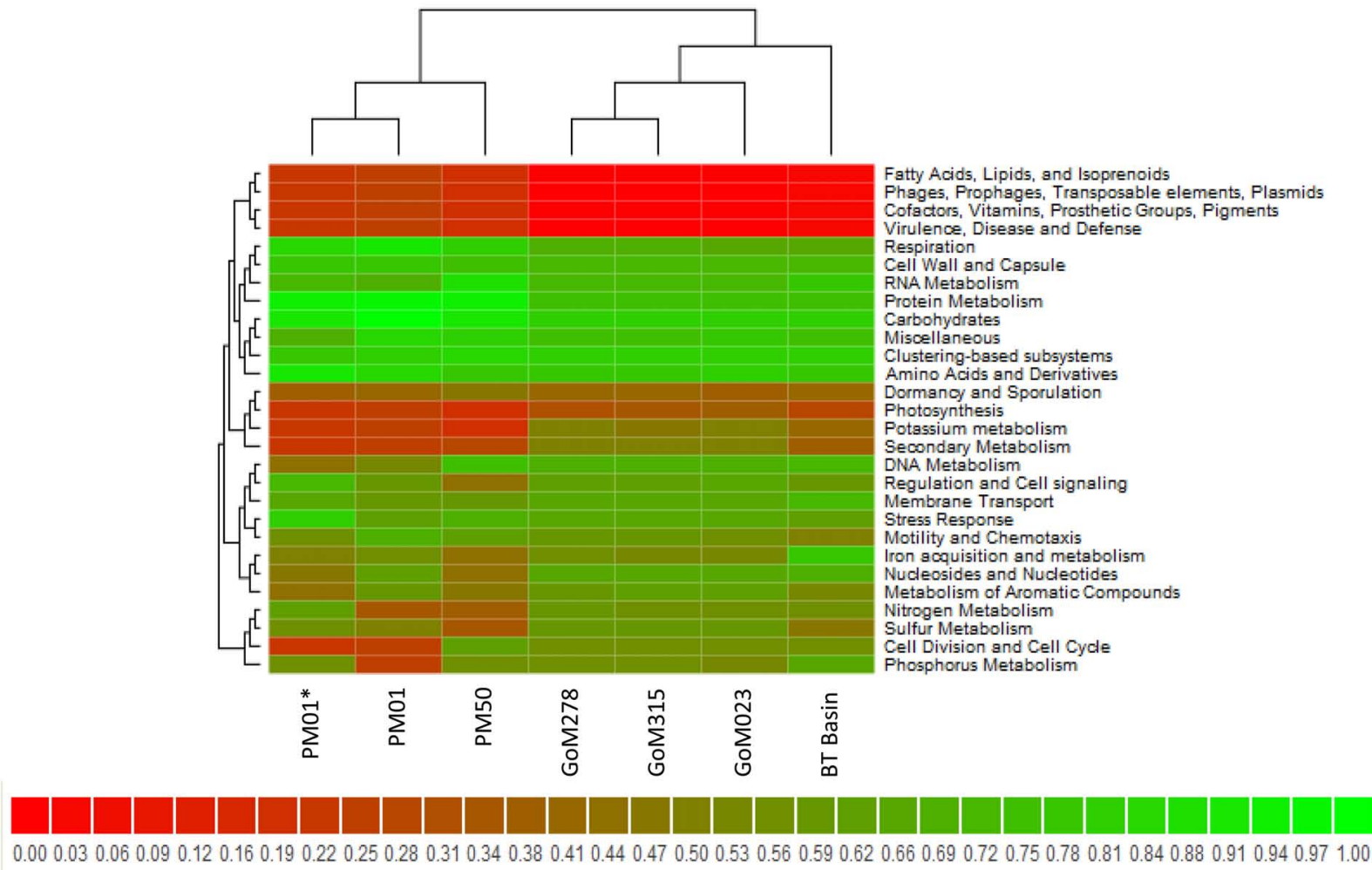

FIGURE 10 | Cross-study comparisons of deep-sea metagenomes.

(A) Principal component analysis using organism classifications (specieslevel) from the current study as well as those from two studies (Biddle et al., 2008,2011 ) reveals clear geographic separation, in addition to a second component of separation that is currently unknown. (B) Hierarchical clustering combined with heat mapping based on subsystem classifications reveals similar partitioning among the three studies compared. 
microorganisms capable of degrading the remaining recalcitrant hydrocarbons that require anaerobic processing. It is also possible, however, that we sampled at a time when the community was just beginning to shift to reflect the increasing importance of anaerobic microbes. Future work involving time series samples and/or the analysis of aerobic metabolites will be necessary to provide further insights.

Anaerobic biodegradation of hydrocarbons is an important biogeochemical process in a variety of deep-subsurface environments (Aitken et al., 2004; Jones et al., 2007; Wawrik et al., 2012). Studies during the last two decades have highlighted the ability of anaerobic microorganisms to metabolize a variety of hydrocarbons, including $n$-alkanes, $n$-alkenes, alicyclic hydrocarbons, and mono- and polycyclic aromatic compounds (for reviews see Boll and Heider, 2010; Widdel and Grundmann, 2010; Widdel et al., 2010). To date, the most well-characterized anaerobic mechanism for hydrocarbon activation and degradation is via addition of the hydrocarbon to the double bond of fumarate ("fumarate addition") catalyzed by glycyl radical enzymes (for reviews see Boll and Heider, 2010; Widdel and Grundmann, 2010). Deltaproteobacteria, in particular, have been implicated in "fumarate addition" of both aromatic and aliphatic hydrocarbons (Widdel et al., 2010). In this study, metagenomic analysis revealed an increase in the percentage of bacterial sequences that represent Deltaproteobacteria associated with the sediment cores closest to the DWH well, where there were higher levels of PAHs (Operational Science Advisory Team, 2010) and detectable levels of alkanes and alkenes. It should be noted that the increase in Deltaproteobacteria is potentially an indirect effect of the increased dead biomass from the oil spill, which cannot be ruled out by this study. In any case, recruitment plots demonstrated that 857 and 547 of the metagenomic sequences mapped onto the Deltaproteobacterial genomes of Desulfatibacillum alkenivorans AK-01 and G. metallireducens GS15 , respectively. The increases in Deltaproteobacteria were also concurrent with an increase in functional genes involved in the anaerobic degradation of hydrocarbons, such as BSS, acetyl-CoA acetyltransferase and benzoyl-CoA reductase. These results suggest that the microbial response to anthropogenic hydrocarbon loading may mirror aspects of microbial communities associated with Gulf of Mexico natural seeps, where Deltaproteobacteria play a dominant role in their biogeochemical activity, including anaerobic hydrocarbon degradation (Lloyd et al., 2010; Orcutt et al., 2010). Most likely, however, the specific genus-level lineages of Deltaproteobacteria will be dependent on the hydrocarbon source present, since the natural gas-rich seeps contain specialized deltaproteobacterial groups for anaerobic methane utilization that are unlikely to thrive in sediments with more recalcitrant oil remnants.

Clone libraries of ass $A$ and $b s s A$ supported the metagenomic analysis. Both genotypes were detected in sediments near the DWH well (GoM278 and GoM315), but not at the unimpacted site (GoM023). The presence of ass $A$ and bss $A$ suggests the potential for both aliphatic and aromatic hydrocarbon activation via "fumarate addition." Although ass A genotypes were detected in sediments from GoM278 and GoM315, alkylsuccinates were not detected in these samples. However, this should not be interpreted as conclusive evidence that aliphatic substrates were not being metabolized. The requisite metabolites are usually in low abundance (typically nM) and transitory and could have easily been further metabolized or been below method detection limits. The alkanoic acid compounds detected in the GoM samples could have been formed via multiple biological pathways, including aerobic and anaerobic transformation of aliphatic hydrocarbons, but they are not highly diagnostic. Despite the non-detection of alkylsuccinates, both $b s s A$ genotypes and the putative benzylsuccinate metabolites were detected in the two sediment cores closest to the spill site, suggesting in situ anaerobic biodegradation of alkylbenzenes. This is consistent with the increased number of genes related to "aromatic metabolism" detected in the corresponding sediments via metagenomic analysis. Benzoate was also detected in GoM278 and GoM315 sediments, suggesting further transformation of the benzylsuccinate derivatives of monoaromatic hydrocarbons (Beller and Spormann, 1997; Leuthner et al., 1998). However, benzoate can be formed during the metabolism of a wide variety of aromatic compounds under aerobic and anaerobic conditions.

Overall, this study took an interdisciplinary approach of investigating the phylogenetic composition and functional potential of Gulf of Mexico deep-sea sediment communities following the DWH oil spill. Based on metagenomic analyses, functional gene clone libraries, and metabolite profiling, the data herein suggest that the presence of PAHs, alkanes, and alkenes may influence the microbial community through the enrichment of Deltaproteobacteria capable of anaerobic hydrocarbon metabolism. This evidence suggests that the microbial communities exposed to anthropogenic hydrocarbon loading in the Gulf of Mexico deepsea sediments likely impacted the bioremediation of the DWH oil spill through anaerobic degradation, which has been previously overlooked. The integrated approach used herein augments other efforts to deduce the fate of the oil spilled in the DWH incident and to assess the impact of the spill on the indigenous microbial communities.

\section{ACKNOWLEDGMENTS}

We would like to thank the following individuals at LBNL that were instrumental in collecting, preserving, and aseptically sectioning the deep-sea sediment cores: Sharon Borglin, Yvette Piceno, Dominique Joyner, Janet Jansson, and Olivia Mason. We would also like to thank Andreas Teske for his thoughtful comments and critical review of the manuscript. This study was supported by the National Science Foundation (MCB-1049411) and (MCB1049409) to PJM and JMS, respectively, by the program SPP 1319 of the Deutsche Forschungsgemeinschaft (grant to BTG in support of MD), and also in part by an NSF grant (MCB-0921265) to AVC. BTG and MD also thank the EPSRC Mass Spectrometry Service at the University of Wales (Swansea) for mass spectrometric analyses.

\section{SUPPLEMENTARY MATERIAL}

The Supplementary Material for this article can be found online at: http://www.frontiersin.org/Microbiological_Chemistry/

10.3389/fmicb.2013.00050/abstract 


\section{REFERENCES}

Aitken, C. M., Jones, D. M., and Larter, S. R. (2004). Anaerobic hydrocarbon biodegradation in deep subsurface oil reservoirs. Nature 431, 291-294.

Aktas, D. F., Lee, J. S., Little, B. J., Ray, R. I., Davidova, I. A., and Lyles, C. N. (2010). Anaerobic metabolism of biodiesel and its impact on metal corrosion. Energ. Fuels 24, 2924-2928.

Atlas, R. M. (1981). Microbial degradation of petroleum hydrocarbons: an environmental perspective. Microbiol. Rev. 45, 180-209.

Beller, H. R., Kane, S. R., Legler, T. C., McKelvie, J. R., Lollar, B. S., Pearson, F., et al. (2008). Comparative assessments of benzene, toluene, and xylene natural attenuation by quantitative polymerase chain reaction analysis of a catabolic gene, signature metabolites, and compound-specific isotope analysis. Environ. Sci. Technol. 42, 6065-6072.

Beller, H. R., and Spormann, A. M. (1997). Anaerobic activation of toluene and o-xylene by addition to fumarate in denitrifying strain T. $J$. Bacteriol. 179, 670-676.

Biddle, J. F., Fitz-Gibbon, S., Schuster, S. C., Brenchley, J. E., and House, C. H. (2008). Metagenomic signatures of the Peru Margin subseafloor biosphere show a genetically distinct environment. Proc. Natl. Acad. Sci. U.S.A. 105, 10583-10588.

Biddle, J. F., White, J. R., Teske, A. P., and House, C. H. (2011). Metagenomics of the subsurface BrazosTrinity Basin (IODP site 1320): comparison with other sediment and pyrosequenced metagenomes. ISME J. 5, 1038-1046.

Biegert, T., Fuchs, G., and Heider, J. (1996). Evidence that anaerobic oxidation of toluene in the denitrifying bacterium Thauera aromatica is initiated by formation of benzylsuccinate from toluene and fumarate. Euro. J. Biochem. 238, 661-668.

Boll, M., and Heider, J. (2010). "Anaerobic degradation of hydrocarbons: mechanisms of $\mathrm{C}-\mathrm{H}$-bond activation in the absence of oxygen," in Handbook of Hydrocarbon and Lipid Microbiology, eds K. Timmis, T. Mcgenity, J. Van Der Meer, and V. De Lorenzo (Berlin: Springer-Verlag), 1011-1024.

Callaghan, A. V., Davidova, I. A., SavageAshlock, K., Parisi, V. A., Gieg, L. M., Suflita, J. M., et al. (2010). Diversity of benzyl- and alkylsuccinate synthase genes in hydrocarbon-impacted environments and enrichment cultures. Environ. Sci. Technol. 44, 72877294.
Callaghan, A. V., Morris, B. E. L., Pereira, I. A. C., McInerney, M. J., Austin, R. N., Groves, J. T., et al. (2012). The genome sequence of Desulfatibacillum alkenivorans $\mathrm{AK}-01$ : a blueprint for anaerobic alkane oxidation. Environ. Microbiol. 14, 101-113.

Callaghan, A. V., Wawrik, B., Ní Chadhain, S. M., Young, L. Y., and Zylstra, G. J. (2008). Anaerobic alkane-degrading strain AK-01 contains two alkylsuccinate synthase genes. Biochem. Biophys. Res. Commun. 366, 142-148.

Colwell, R. K. (2006). EstimateS: Statistical Estimation of Species Richness and Shared Species for Samples, Version 8. Available at: http://purl.oclc.org/estimates

Davidova, I. A., Gieg, L. M., Nanny, M. Kropp, K. G., and Suflita, J. M. (2005). Stable isotopic studies of n-alkane metabolism by a sulfate-reducing bacterial enrichment culture. Appl. Environ. Microbiol. 71, 81748182.

D’Hondt, S., Jørgensen, B. B., Miller, D. J., Batzke, A., Blake, R., Cragg, B. A. et al. (2004). Distributions of microbial activities in deep subseafloor sediments. Science 306, 2216-2221.

D’Hondt, S., Spivack, A. J., Pockalny, R., Ferdelman, T. G., Fischer, J P., Kallmeyer, J., et al. (2009). Subseafloor sedimentary life in the South Pacific Gyre. Proc. Natl. Acad. Sci. U.S.A. 106, 11651-11656.

dos Santos, V., Sabirova, J., Timmis, K., Yakimov, M., and Golyshin, P. (2010). "Alcanivorax borkumensis," in Handbook of Hydrocarbon and Lipid Microbiology, eds K. Timmis, T. Mcgenity, J. Van Der Meer, and V. De Lorenzo.(Berlin: SpringerVerlag), 1011-1024.

Duncan, K. E., Gieg, L. M., Parisi, V. A., Tanner, R. S., Tringe, S. G., Bristow, J., et al. (2009). Biocorrosive thermophilic microbial communities in Alaskan North Slope oil facilities. Environ. Sci. Technol. 43, 79777984.

Egland, P. G., Pelletier, D. A., Dispensa, M., Gibson, J., and Harwood, C. S. (1997). A cluster of bacterial genes for anaerobic benzene ring biodegradation. Proc. Nat. Acad. Sci. U.S.A. 94, 6484-6489.

Elshahed, M. S., Gieg, L. M., McInerney, M. J., and Suflita, J. M. (2001). Signature metabolites attesting to the in situ attenuation of alkylbenzenes in anaerobic environments. Environ. Sci. Technol. 35, 682-689.

Fritsche, W., and Hofrichter, M. (2008). "Aerobic degradation by microorganisms," in Biotechnology: Environmental Processes II, Vol. 11b, 2nd Edn, eds
H. J. Rehm and G. Reed (Weinheim: Wiley-VCH Verlag GmbH), 146-164. Gieg, L. M., and Suflita, J. M. (2005). "Metabolic indicators of anaerobic hydrocarbon biodegradation in petroleum-laden environments," in Petroleum Microbiology, eds B. Ollivier, and M. Magot (Washington, DC: ASM Press), 356-371.

Grundmann, O., Behrends, A., Rabus, R., Amann, J., Halder, T., Heider, J., et al. (2008). Genes encoding the candidate enzyme for anaerobic activation of n-alkanes in the denitrifying bacterium, strain $\mathrm{HxN1}$. Environ. Microbiol. 10, 376-385.

Haddock, J. D. (2010). "Aerobic degradation of aromatic hydrocarbons: enzyme structures and catalytic mechanisms," in Handbook of Hydrocarbon and Lipid Microbiology, eds K. Timmis, T. Mcgenity, J. Van Der Meer, and V. De Lorenzo (Berlin: Springer-Verlag), 1057-1069.

Hara, A., Syutsubo, K., and Harayama, S. (2003). Alcanivorax which prevails in oil-contaminated seawater exhibits broad substrate specificity for alkane degradation. Environ. Microbiol. 5, 746-753.

Harayama, S., Kishira, H., Kasai, Y., and Shutsubo, K. (1999). Petroleum biodegradation in marine environments. J. Mol. Microbiol. Biotechnol. 1, 63-70.

Hazen, T. C., Dubinsky, E. A., Desantis, T. Z., Andersen, G. L., Piceno, Y. M., Singh, N., etal. (2010). Deepsea oil plume enriches indigenous oil-degrading bacteria. Science 330, 204-208.

Head, I. M., Jones, D. M., and Röling, W. F. M. (2006). Marine microorganisms make a meal of oil. Nat. Rev. Microbiol. 4, 173-182.

Hu, Y., Fu, C., Yin, Y., Cheng, G., Lei, F., Yang, X., et al. (2010). Construction and preliminary analysis of a deepsea sediment metagenomic fosmid library from Qiongdongnan Basin, South China Sea. Mar. Biotechnol. 12, 719-727.

Jernelov, A., and Linden, O. (1981). Ixtoc I: a case study of the world's largest oil spill. Ambio 10, 299-306.

Jones, D., Head, I., Gray, N., Adams, J., Rowan, A., Aitken, C., et al. (2007). Crude-oil biodegradation via methanogenesis in subsurface petroleum reservoirs. Nature 451, 176-180.

Jørgensen, B. B. (2011). Deep subseafloor microbial cells on physiological standby. Proc. Natl. Acad. Sci. U.S.A. 108, 18193-18194.

Joye, S. B., Boetius, A., Orcutt, B. N., Montoya, J. P., Schulz, H. N., Erickson, M. J., et al. (2004). The anaerobic oxidation of methane and sulfate reduction in sediments from Gulf of Mexico cold seeps. Chem. Geol. 205, 219-238.

Kallmeyer, J., Pockalny, R., Adhikari, R. R., Smith, D. C., and D'Hondt, S. (2012). Global distribution of microbial abundance and biomass in subseafloor sediment. Proc. Natl. Acad. Sci. U.S.A. 109, 16213-16216.

Kasai, Y., Kishira, H., Syutsubo, K., and Harayama, S. (2001). Molecular detection of marine bacterial populations on beaches contaminated by the Nakhodka tanker oil-spill accident. Environ. Microbiol. 3, 246-255.

Kessler, J. D., Valentine, D. L., Redmond, M. C., Du, M., Chan, E. W., Mendes, S. D., et al. (2011). A persistent oxygen anomaly reveals the fate of spilled methane in the deep Gulf of Mexico. Science 331, 312-315.

Kim, S., and Kwon, K. (2010). "Marine, hydrocarbon-degrading Alphaproteobacteria," in Handbook of Hydrocarbon and Lipid Microbiology, eds K. Timmis, T. Mcgenity, J. Van Der Meer, and V. De Lorenzo (Berlin: Springer-Verlag), 1707-1714.

Kropp, K. G., Davidova, I. A., and Suflita, J. M. (2000). Anaerobic oxidation of $n$-dodecane by an addition reaction in a sulfate-reducing bacterial enrichment culture. Appl. Environ. Microbiol. 66, 5393-5398.

Kumar, S., Nei, M., Dudley, J., and Tamura, K. (2008). MEGA: a biologist-centric software for evolutionary analysis of DNA and protein sequences. Brief. Bioinform. 9, 299-306.

Leuthner, B., Leutwein, C., Schulz, H., Hörth, P., Haehnel, W., Schiltz, E., et al. (1998). Biochemical and genetical characterization of benzylsuccinate synthase from Thauera aromatica: a new glycyl radical enzyme catalyzing the first step in anaerobic toluene metabolism. Mol. Microbiol. 28, 615-628.

Lloyd, K. G., Albert, D. B., Biddle, J. F., Chanton, J. P., Pizarro, O., and Teske, A. (2010). Spatial structure and activity of sedimentary microbial communities underlying a Beggiatoa spp. mat in a Gulf of Mexico hydrocarbon seep. PLoS ONE 5:e8738. doi: 10.1371/journal.pone.0008738

Lloyd, K. G., Lapham, L., and Teske, A. (2006). An anaerobic methaneoxidizing community of ANME-1b archaea in hypersaline Gulf of Mexico sediments. Appl. Environ. Microbiol. 72, 7218-7230.

Lovley, D. R., Giovannoni, S. J., White, D. C., Champine, J. E., Phillips, E. J. P., Gorby, Y. A., et al. (1993). Geobacter metallireducens gen. nov. sp. nov., 
a microorganism capable of coupling the complete oxidation of organic compounds to the reduction of iron and other metals. Arch. Microbiol. 159, 336-344.

Mason, O. U., Hazen, T. C., Borglin, S., Chain, P. S. G., Dubinsky, E. A., Fortney, J. L., et al. (2012). Metagenome, metatranscriptome and single-cell sequencing reveal microbial response to Deepwater Horizon oil spill. ISME J. 6, 1715-1727.

Meyer, F., Paarmann, D., D'souza, M., Olson, R., Glass, E. M., Kubal, M., etal. (2008). The metagenomics RAST server - a public resource for the automatic phylogenetic and functional analysis of metagenomes. BMC Bioinformatics 9:386. doi: 10.1186/1471-2105-9-386

Muyzer, G., De Waal, E. C., and Uitterlinden, A. G. (1993). Profiling of complex microbial populations by denaturing gradient gel electrophoresis analysis of polymerase chain reaction-amplified genes coding for 16S rRNA. Appl. Environ. Microbiol. 59, 695-700.

Oka, A. R., Phelps, C. D., Zhu, X., Saber, D. L., and Young, L. (2011). Dual biomarkers of anaerobic hydrocarbon degradation in historically contaminated groundwater. Environ. Sci. Technol. 45, 3407-3414.

Operational Science Advisory Team. (2010). Summary Report for Sub-Sea and Sub-Surface Oil and Dispersant Detection: Sampling and Monitoring. December 17, 2010.

Orcutt, B. N., Joye, S. B., Kleindienst, S., Knittel, K., Ramette, A., Reitz,
A., etal. (2010). Impact of natural oil and higher hydrocarbons on microbial diversity, distribution, and activity in Gulf of Mexico coldseep sediments. Deep Sea Res. Part 2 Top. Stud. Oceanogr. 57, 20082021.

Parisi, V. A., Brubaker, G. R., Zenker, M. J., Prince, R. C., Gieg, L. M., Da Silva, M. L. B., et al. (2009). Field metabolomics and laboratory assessments of anaerobic intrinsic bioremediation of hydrocarbons at a petroleum-contaminated site. Microb. Biotechnol. 2, 202-212.

Ramseur, J. L. (2010). Deepwater Horizon Oil Spill: the Fate of the Oil. Washington, DC: Congressional Research Service.

Rojo, F. (2010). "Enzymes for aerobic degradation of alkanes," in Handbook of Hydrocarbon and Lipid Microbiology, eds K. Timmis, T. Mcgenity, J. Van Der Meer, and V. De Lorenzo (Berlin: Springer-Verlag), 781-797.

Schneiker, S., Martins Dos Santos, V., Bartels, D., Bekel, T., Brecht, M., Buhrmester, J., etal. (2006). Genome sequence of the ubiquitous hydrocarbondegrading marine bacterium Alcanivorax borkumensis. Nat. Biotechnol. 24, 997-1004.

Seth-Smith, H. (2010). 'Slick' operations. Nat. Rev. Microbiol. 8, 538.

So, C. M., and Young, L. (1999). Isolation and characterization of a sulfate-reducing bacterium that anaerobically degrades alkanes. Appl. Environ. Microbiol. 65, 29692976.

Wawrik, B., Mendivelso, M., Parisi, V. A., Suflita, J. M., Davidova, I. A.,
Marks, C. R., et al. (2012). Field and laboratory studies on the bioconversion of coal to methane in the San Juan Basin. FEMS Microbiol. Ecol. 81, 26-42.

Widdel, F., and Grundmann, O. (2010). "Biochemistry of the anaerobic degradation of non-methane alkanes," in Handbook of Hydrocarbon and Lipid Microbiology, eds K. Timmis, T. Mcgenity, J. Van Der Meer, and V. De Lorenzo (Berlin: Springer-Verlag), 909-924.

Widdel, F., Knittel, K., and Galushko, A. (2010). "Anaerobic hydrocarbondegrading microorganisms: an overview," in Handbook of Hydrocarbon and Lipid Microbiology, eds K. Timmis, T. Mcgenity, J. Van Der Meer and V. De Lorenzo (Berlin: Springer-Verlag), 1997 2021.

Yagi, J. M., Suflita, J. M., Gieg, L. M., DeRito, C. M., Jeon, C. O., and Madsen, E. L. (2010). Subsurface cycling of nitrogen and anaerobic aromatic hydrocarbon biodegradation revealed by nucleic acid and metabolic biomarkers. Appl. Environ. Microbiol. 76, 3124 3134.

Yakimov, M. M., Denaro, R., Genovese, M., Cappello, S., D’Auria, G., and Chernikova, T. N., et al. (2005). Natural microbial diversity in superficial sediments of Milazzo Harbor (Sicily) and community successions during microcosm enrichment with various hydrocarbons. Environ. Microbiol. 7, 1426-1441.

Yakimov, M. M., Golyshin, P. N., Lang, S., Moore, E. R. B., Abraham, W. R.,
Lünsdorf, H., et al. (1998). Alcanivorax borkumensis gen. nov., sp. nov., a new, hydrocarbon-degrading and surfactant-producing marine bacterium. Int. J. Syst. Bacteriol. 48, 339-348.

Conflict of Interest Statement: The authors declare that the research was conducted in the absence of any commercial or financial relationships that could be construed as a potential conflict of interest.

Received: 17 December 2012; accepted: 21 February 2013; published online: 15 March 2013.

Citation: Kimes NE, Callaghan AV, Aktas $D F$, Smith WL, Sunner J, Golding BT, Drozdowska M, Hazen TC, Suflita JM and Morris PJ (2013) Metagenomic anal$y$ sis and metabolite profiling of deep-sea sediments from the Gulf of Mexico following the Deepwater Horizon oil spill. Front. Microbiol. 4:50. doi: 10.3389/fmicb.2013. 00050

This article was submitted to Frontiers in Microbiological Chemistry, a specialty of Frontiers in Microbiology.

Copyright (c) 2013 Kimes, Callaghan, Aktas, Smith, Sunner, Golding, Drozdowska, Hazen, Suflita and Morris. This is an open-access article distributed under the terms of the Creative Commons Attribution License, which permits use, distribution and reproduction in other forums, provided the original authors and source are credited and subject to any copyright notices concerning any thirdparty graphics etc. 